\title{
Decreased Rhythmic GABAergic Septal Activity and Memory-Associated $\theta$ Oscillations after Hippocampal Amyloid- $\beta$ Pathology in the Rat
}

\author{
Vincent Villette, ${ }^{1,2}$ Frédérique Poindessous-Jazat, ${ }^{1,2}$ Axelle Simon, ${ }^{1,2}$ Clément Léna, ${ }^{3}$ Elodie Roullot, ${ }^{4}$ Brice Bellessort, ${ }^{1,2}$ \\ Jacques Epelbaum, ${ }^{1,2}$ Patrick Dutar, ${ }^{1,2}$ and Aline Stéphan ${ }^{1,2}$ \\ ${ }^{1}$ Inserm Centre de Psychiatrie et Neurosciences, Unité Mixte de Recherche (UMR) 894, 75014 Paris, France, 2Université Paris Descartes, Faculté de \\ Médecine, 75005 Paris, France, ${ }^{3}$ Laboratoire de Neurobiologie, UMR 8544, Ecole Normale Supérieure, 75005 Paris, France, and ${ }^{4}$ Ecole Spéciale de \\ Mécanique et d'Electricité-Sudria, Pôle de Recherche en Imagerie Appliquée à la Médecine, 94200 Ivry sur Seine, France
}

The memory deficits associated with Alzheimer's disease result to a great extent from hippocampal network dysfunction. The coordination of this network relies on theta $(\theta)$ oscillations generated in the medial septum. Here, we investigated in rats the impact of hippocampal amyloid $\beta(\mathrm{A} \beta)$ injections on the physiological and cognitive functions that depend on the septohippocampal system. Hippocampal $\mathrm{A} \beta$ injections progressively impaired behavioral performances, the associated hippocampal $\theta$ power, and $\theta$ frequency response in a visuospatial recognition test. These alterations were associated with a specific reduction in the firing of the identified rhythmic bursting GABAergic neurons responsible for the propagation of the $\theta$ rhythm to the hippocampus, but without loss of medial septal neurons. Such results indicate that hippocampal $\mathrm{A} \beta$ treatment leads to a specific functional depression of inhibitory projection neurons of the medial septum, resulting in the functional impairment of the temporal network.

\section{Introduction}

Deterioration of hippocampal function contributes to the memory deficits associated with Alzheimer's disease (AD) (Scheibel, 1979; Small et al., 1999; Wang et al., 2009). The processes by which this function is disrupted in AD are not fully understood, but the most widely accepted hypothesis involves the amyloid beta $(A \beta)$ cascade and $A \beta$ accumulation in limbic areas (Golde, $2005)$. Indeed, the neuronal expression of the human form of the amyloid precursor protein in transgenic mice (Games et al., 1995; Chin et al., 2005; Faure et al., 2009) or A $\beta$ peptide microinjection in rodents (Flood et al., 1991; Stéphan et al., 2001, 2003) elicits several AD-like abnormalities, including amyloid plaques, neuroinflammation, neuritic dystrophy, aberrant sprouting of axon terminals, synaptic plasticity deficits, and the impairment of learning and memory.

\footnotetext{
Received Dec. 19, 2009; revised May 26, 2010; accepted June 22, 2010.

Financial support was provided to V.V. by the French Educational Ministry and to A.S. by the France Alzheimer Foundation. We thank A. Cougnon, D. Dumoulin, and D. Bergerot for animal care. We thank S. Garcia and N. Fourcaud-Trocmé from OpenElectrophy and P. Zizzari, S. Peineau, G. Lepousez, Y. Morvan, C. Rose, and P. Facchinetti for help with analyses. We also thank Dr. M.H. Bassant for helpful comments regarding the manuscript and S. E Mestikawy and E. Herzog for the gift of VGLUT1 antibodies. This manuscript was prepared with editorial help from Gap Junction.

The authors declare that they have no actual or potential conflict of interest, financial or otherwise, related to the present work. The data contained in this work were not submitted elsewhere. Experimental procedures and the manuscript were approved by all authors.

Correspondence should be addressed to either of the following: Vincent Villette, Inserm Centre de Psychiatrie et Neurosciences, UMR 894, 2 Ter Rue d'Alésia, 75014 Paris, France, E-mail: vincent.villette@inserm.fr; or Aline Stéphan, Institut de Génétique et de Biologie Moléculaire et Cellulaire, Université de Strasbourg, Parc d'Innovation, 1 Rue Laurent Fries, Boîte Postale 10142, 67404 IIIkirch, France, E-mail: aline.stephan@igbmc.fr.

DOI:10.1523/JNEUROSCI.6284-09.2010

Copyright $(\odot 2010$ the authors $\quad 0270-6474 / 10 / 3010991-13 \$ 15.00 / 0$
}

The normal function of hippocampus is strongly dependent on a $4-10 \mathrm{~Hz}$ frequency oscillatory activity, namely the theta rhythm $(\theta)$. By controlling the spike timing necessary for the coding of neuronal ensembles, the hippocampal $\theta$ rhythm is involved in various cognitive processes (Vertes et al., 2004). The medial septum-diagonal band of Broca complex is critically involved in the generation and propagation of the $\theta$ rhythm to the hippocampus (Bullock et al., 1990). The septohippocampal pathway contains GABAergic, glutamatergic, and cholinergic neurons (Köhler et al., 1984; Frotscher and Léránth, 1985; Manns and Squire, 2001; Sotty et al., 2003). The $\theta$ oscillation is propagated by numerous bursting neurons that project to the hippocampus, fire rhythmically at this frequency (Dutar et al., 1986; Stewart and Fox, 1989; Vertes and Kocsis, 1997), and are phase locked to $\theta$. The GABAergic nature of these rhythmic neurons has been recently proven in vitro (Sotty et al., 2003) and in vivo (Borhegyi et al., 2004; Bassant et al., 2005; Varga et al., 2008). In contrast, septal cholinergic and glutamatergic neurons do not display such a rhythmic firing pattern but rather a slowfiring pattern in vitro and in vivo (Griffith and Matthews, 1986; Gorelova and Reiner, 1996; Alreja et al., 2000; Sotty et al., 2003; Simon et al., 2006). Their phase relationship with $\theta$ waves has not been accurately examined in vivo. In $\mathrm{AD}$, a cholinergic septohippocampal degeneration has been assessed but does not seem to account for much of the cognitive impairments in the early disease (Chappell et al., 1998). However, little effort has been made to investigate the role of $A \beta$ injection on other neuronal subpopulations in the medial septum, in particular those involved in $\theta$ rhythmic activity and associated cognitive functions. 
Herein, we explore whether the $\mathrm{A} \beta$-dependent neuronal alterations associated with cognitive deficits are related to aberrant neuronal activity in medial septum-diagonal band neurons. For this purpose, we induced long-lasting $\mathrm{A} \beta$ aggregates in the rat hippocampus and assessed cognitive dysfunction and changes in $\theta$ activity. We present evidence that hippocampal A $\beta$ pathology results in changes in the $\theta$-related activity of medial septumdiagonal band neurons, depending on their firing patterns, phase locking, and neurochemical identities. These lead to decreased septal GABAergic rhythmic activity, together with decline in hippocampal $\theta$ oscillation and memory functions.

\section{Materials and Methods}

Male Sprague Dawley rats ( $n=68,270-300 \mathrm{~g}$ of body weight; Charles River) were housed in conformity with the guidelines of the local animal care and use committee. They were housed three per cage in a temperature-controlled environment under a $12 \mathrm{~h}$ light/dark cycle (lights on: 7:00 A.M. Greenwich Mean Time +1). Experiments were performed according to the guidelines of the French Act for Animal Care and Experimentation. All efforts were made to minimize pain and suffering and to reduce the number of animals used.

Microinjection guide and local field potential electrode implantation. Rats were anesthetized with pentobarbital (60 mg/kg, i.p.) and placed in a stereotaxic frame. Supplementary injections of anesthetic were provided as needed during surgery. All incision sites and pressure points were swabbed with lidocaine before surgery. Body temperature was maintained with a heating pad controlled by a rectal thermal probe. A liquid bonding resin (Superbond; Sun Medical) was applied to the cleaned and dried skull surface. For local field potential (LFP) recordings, wide-field monopolar electrodes were placed bilaterally on top of the hippocampus [anteroposterior (AP): 4.5; lateral (L): \pm 4 ; dorsoventral (DV): cortical surface] (Paxinos and Watson, 1986) and on the occipital crest as a reference. The electrodes were soldered to a connector. For subsequent multiple $A \beta$ injections, two $8.5 \mathrm{~mm}$ guide cannulas (23 gauge) were implanted bilaterally (AP: 2.8 and 3.8 ; L: \pm 1.5 ; DV: 1.0 ) (Paxinos and Watson, 1986). The guides, which contain 30 gauge obturators, and electrodes were firmly attached to the rat skull using dental cement. Intramuscular antibiotic treatment (cefuroxime, $60 \mathrm{mg} / \mathrm{kg}$; GlaxoSmithKline) was administered every other day during the first 6 days of the recovery period and once a week for the rest of the experiment.

Injection of $A \beta$ or vehicle solution. To model focal $A \beta$ pathology in the dorsal hippocampus in vivo, we used a nontransgenic model consisting of the simultaneous microinjection of $A \beta 40$ and $A \beta 42$ at a ratio of 2:1 that mimics the seeding role of $A \beta 42$ in accelerating aggregation in the presence of a metastable level of soluble A $\beta 40$ (Jarrett and Lansbury, 1993). This combination has previously been shown to induce long-lasting A $\beta$ aggregates associated with dysfunctional synaptic plasticity, inflammation, and learning deficits (Stéphan et al., 2001, 2003). A $\beta$ injections were carried out at eight sites under isoflurane anesthesia (0.5\%; Baxter) using 29 gauge stainless steel needles inserted through four previously implanted guides located 3.2 and $2.4 \mathrm{~mm}$ below the brain surface for the two anterior ones and 2.8 and $2.0 \mathrm{~mm}$ below the brain surface for the two posterior ones. The $\mathrm{A} \beta$ group $(n=34)$ received $0.25 \mu$ l per site of $\mathrm{A} \beta 40$ $(20 \mu \mathrm{g} / \mu \mathrm{l})$ and $\mathrm{A} \beta 42(10 \mu \mathrm{g} / \mu \mathrm{l})$ (Bachem) in vehicle solution $(30 \%$ acetonitrile and $0.05 \%$ trifluoroacetate in sodium chloride, $0.9 \%$ ). Control rats $(n=34)$ were injected with $0.25 \mu$ l of the vehicle solution per site. The needle was left in place for $2 \mathrm{~min}$ before the injection, and peptides were injected slowly over a period of $2 \mathrm{~min}$. The needle was left in for a further $2 \mathrm{~min}$ period before being slowly retracted to prevent backwash up the cannula tract.

Behavioral paradigm. Rats were evaluated for attention capacity and recognition memory using a spontaneous visuospatial recognition task (vehicle group, $n=7 ; \mathrm{A} \beta$ group, $n=9$ ) based on the spontaneous exploration of items from different mnesic classes (Fig. 1A). Sessions composed of a training trial and a test trial of 5 min each, spaced $1 \mathrm{~h}$ apart, occurred in an open circular area (floor diameter: $20 \mathrm{~cm}$; top diameter: $40 \mathrm{~cm}$; height: $36 \mathrm{~cm})$. Six different flat items $\left(5 \mathrm{~cm}^{2}\right.$ each) were placed over the area and two spots were left empty as follows: (1) long term stimuli (LT) were always placed in the same position for a given rat; (2) short term stimuli (ST) were conserved (stimulus and position) between the two trials of a session but differed (stimulus and position) from one session to another; (3) new stimuli (NS) were different (stimulus and position) for each trial; 4) empty positions (EP) differed in position at each trial. The two last classes of items, NS and EP, were pooled into a single group (novel items) because they both exhibit spatial novelty at each trial. All items were preselected during a pilot experiment for their ability to induce the same level of spontaneous interest. Exposure to the different items was normalized between rats and groups. After a $10 \mathrm{~min}$ habituation session in the area for three consecutive days, trial sessions were started the day before $\mathrm{A} \beta$ injections, with training and test trials. On the day of injection (day 0 ), testing was started $1 \mathrm{~h}$ after the last injection. Rats were subsequently tested between 9 and 12 A.M. every other day, from day 1 (D1) to D21.

During behavioral testing, rats explore the circular area and rear on stimuli. Since the development of amyloid pathology has been associated with hyperactivity and stereotypic behavior in previous studies (Ambrée et al., 2006, Richter et al., 2008), the sensorimotor activity of rats in the experimental area was analyzed during the learning course (during baseline, days 1,7, 15, and 21). Episodes of rearing for item exploration were defined as the completion of the following exploratory movement pattern: initiation of climbing, climbing, rearing (in which the rat "stands" on its back feet with its forepaws contacting the wall, its body extended and its nose directed toward the stimulus at a maximum distance of $2 \mathrm{~cm}$ from it), and descent. The number of rearing episodes per item was scored and analyzed as the main index of exploration. It was then used to calculate the familiarity preference index, i.e., the number of rearing episodes related to LT items as the percentage of the number of rearing episodes related to all items, and the novelty preference index $(\mathrm{N})$, i.e., the number of visits to novel items as the percentage of the number of visits to all items. The time spent on each rearing episode, an index of behavior potentially affecting memory and LFP results, was also independently scored from videotapes (40 ms frame resolution) for exploration of five stimuli per rat. Two others groups of rats were tested that were composed of vehicle-injected $(n=3)$ and amyloid-injected $(n=4)$ rats. These rats were exposed to the same experimental context except for the omission of the stimuli, i.e., they had no stimuli recognition learning to achieve to test any potential learning effect on $\theta$ power. Data are presented as the mean \pm SEM of the percentage of visits to a given class of items by each group of animals.

LFP recordings. During every behavioral session (vehicle: $n=8$; $\mathrm{A} \beta$ : $n=9$ ), bilateral corticohippocampal LFP signals were collected on a personal computer via a Cambridge Electronic Design 1401 interface using the Spike 2 software (sampling rate, $100 \mathrm{~Hz}$ ). After the analysis of LFP episodes ( $7 \mathrm{~s}$ episodes, five episodes per rat per day) by fast Fourier transform (FFT), the power spectra obtained during exploratory behavior were computed over the $0-50 \mathrm{~Hz}$ range at a resolution of $0.4 \mathrm{~Hz}$. The frequency with peak power in the $6-9 \mathrm{~Hz}$ band was taken to be the $\theta$ oscillation. Frequency were ranged on FFT (Spike 2) by summing power values of nonoverlapping intervals with cutoffs from 1.95 to $5.86 \mathrm{~Hz}$ for 2-6 $\mathrm{Hz}$ band, from 5.878 to $8.98 \mathrm{~Hz}$ for $6-9 \mathrm{~Hz}$ band, and bins from 8.99 to $49.61 \mathrm{~Hz}$ for $9-50 \mathrm{~Hz}$ band. Filtered traces in Figure 1, $D$ and $E$, were obtained after a Butterworth bandpass filtering with cutoffs at 6 and $9 \mathrm{~Hz}$ for the $\theta$ band. To ensure that the modulation of the $\theta$ frequency was not related to a variation in running speed, peak $\theta$ frequency was measured while the rat was rearing in front of the items, when little or no locomotion was taking place. To quantify oscillatory activity, the normalized power of frequency bands was calculated as the relative power in a band when compared to the total power in all frequency bands for each epoch. To visualize systematic variations in $\theta$ frequency across the different classes of stimuli presented, 3 s episodes of LFP were analyzed according to the stimulus explored. At least 12 episodes per class per day per group were averaged. Group data are represented as the mean \pm SEM of the normalized power spectrum for a given band. Fluctuations in other $\theta$ frequencies than the dominant $6-9 \mathrm{~Hz}$ were investigated with time frequency analysis of a larger $\theta$ band $(4-10 \mathrm{~Hz})$ on the LFP collected $21 \mathrm{~d}$ after injections. Analyses were performed using OpenElectrophy tools, an electrophysiological data- and analysis-sharing framework open source (http://neuralensemble.org/trac/OpenElectrophy). A continuous 
A
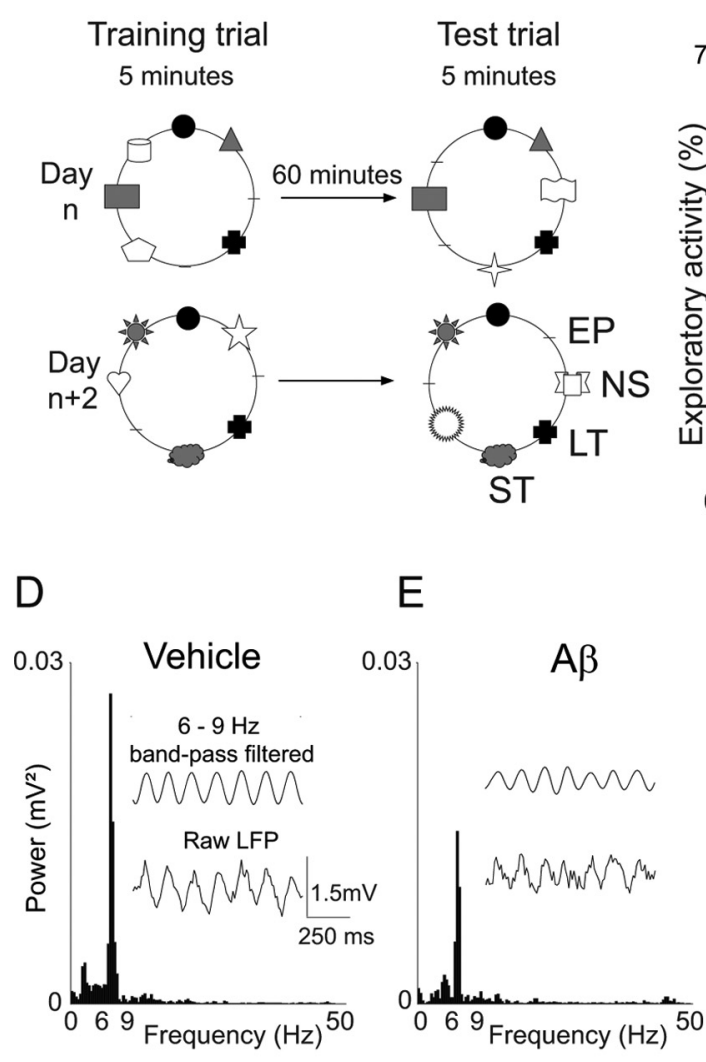

B

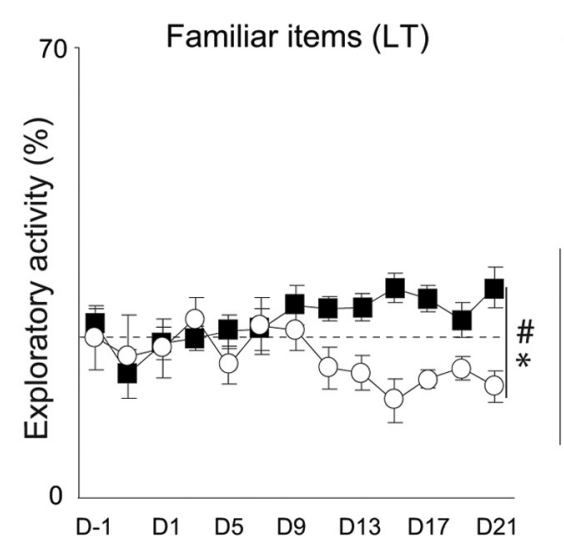

$\mathrm{F}$

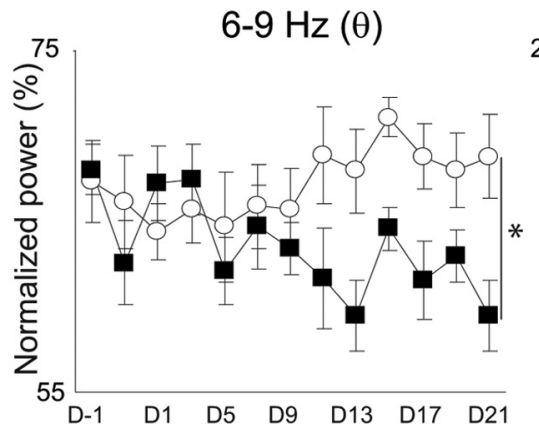

C

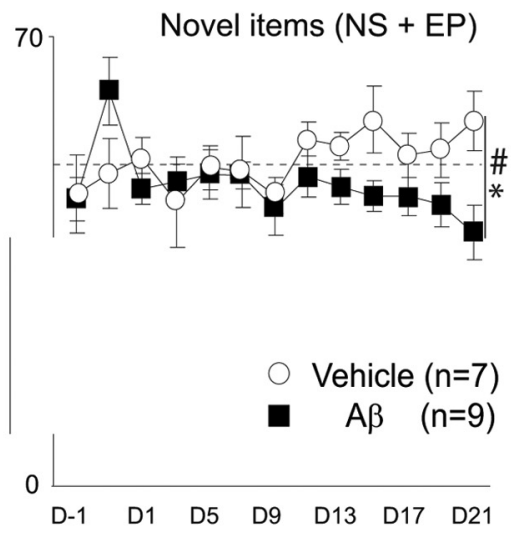

G
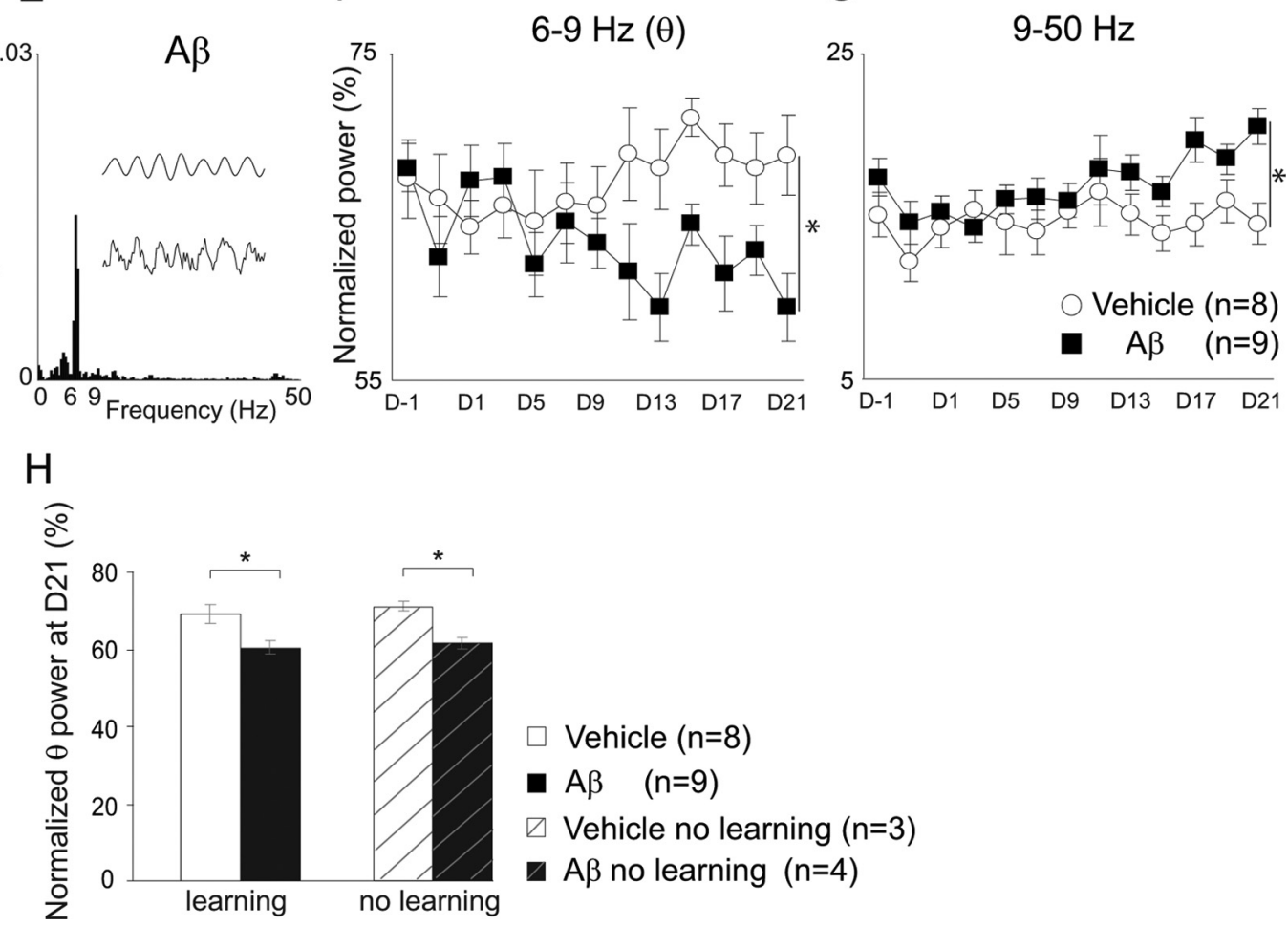

Figure 1. Parallel progressive recognition memory and $\theta$ rhythm power impairments during test sessions after hippocampal $A \beta$ injection. $\boldsymbol{A}$, Representative diagrams of two successive sessions in the visuospatial recognition task. Sessions were composed of $5 \mathrm{~min}$ training and test trials, spaced $1 \mathrm{~h}$ apart. Six different flat items and two empty positions were placed over a circular area as follows: Iong term stimuli, LT, were always in the same position for a given rat; new stimuli, NS, were changed for each trial; the empty position, EP, was changed for each trial. The two latter classes were pooled into a single group (novel) because they share systematic spatial novelty. Short term stimuli, ST, were conserved during the course of a session but changed in subsequent sessions. They were used as second-level recognition discriminators, but no differences in visits to these items were observed in this study, and they were not taken into consideration in further analyses. $\boldsymbol{B}, \boldsymbol{C}$, Exploration of familiar (LT) items $(\boldsymbol{B})$, and novel (NS and EP) items ( $\boldsymbol{C}$ ) for vehicle-treated $(n=7$, open circle) and A $\beta$-treated animals ( $n=9$, black square) from $1 \mathrm{~d}$ before to $21 \mathrm{~d}$ after injections.

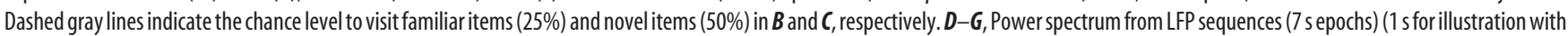
raw and Butterworth-filtered LFP traces) recorded during visits to items on the 21 st day after vehicle $(\boldsymbol{D})$ or $A \beta(\boldsymbol{E})$ injections. $\boldsymbol{F}, \boldsymbol{G}$, Quantification of normalized power, from $1 \mathrm{~d}$ before to $21 \mathrm{~d}$ after injection. Normalized power (percentage) of $6-9 \mathrm{~Hz}(\boldsymbol{F})$ and $9-50 \mathrm{~Hz}(\boldsymbol{G})$ bands for vehicle group $(n=8$, open circle) and $\mathrm{A} \beta$ group ( $n=9$, black square). Data are represented as mean \pm SEM. The dependence of the activity with respect to stimulus class was determined by linear regression analyses; ${ }^{*} p<0.05$. Vh- LT: $F_{(1,89)}=9.7, p<0.05 ; \mathrm{Vh}-\mathrm{NS}: F_{(1,89)}=4.27, p<0.05 ; \mathrm{A} \beta$-LT: $F_{(1,115)}=15.77, p<0.05 ; \mathrm{A} \beta$-NS: $F_{(1,115)}=8.43, p<0.05$. Repeated measures ANOVA with group and time as factors $\left(\mathrm{LT}\right.$ items: $F_{(12,168)}=3.22 ; \mathrm{NS}$ items: $\left.F_{(12,168)}=1,75 ;{ }^{\#} p<0.05\right) . \boldsymbol{H}$, Quantification of normalized $\theta$ power $21 \mathrm{~d}$ after injection in rats that achieved stimuli recognition task (left) for vehicle $(n=8$, white bar) and amyloid ( $n=9$, black bar) and in rats with no learning (i.e., no stimuli recognition) (right) for vehicle ( $n=3$, white striped bar) and amyloid ( $n=4$, black striped bar) (D21, unpaired $t$ test, no learning: $\left.t_{(1-5)}=-8.357 ; p<0.5\right)$. Hippocampal $A \beta$ injections induced progressive recognition memory and $\theta$ rhythm power impairments independently of learning per se.

Morlet wavelet transform was applied to obtain spectrograms of frequencies in the $4-10 \mathrm{~Hz}$ band. Twelve time-frequency maps by group and by classes were obtained during 3 s periods before, during, and after overlapping stimuli exploration.

To ascertain that frequency measurement was not affected by a systematic speed difference across rats (Jeewajee et al., 2008), analyses of total distance traveled, the average speed during activity (immobility periods $(v=0)$ were excluded), and positive acceleration (periods of deceleration or null acceleration were excluded) periods were also performed on the 21st day after injections. The path of the rats in the area was obtained according to $x$ and $y$ coordinates of the rat's head using homemade software for the duration of the entire test trial (300 s) at a 
resolution of 25 image/s. Immobility periods were defined when instantaneous speed was null. Paths, distance, speed, acceleration, and immobility periods were characterized for seven rats per group. The total distance traveled, the average speed during activity periods (immobility periods were excluded), and positive acceleration are displayed as mean \pm SEM.

Single-unit electrophysiology. At the end of the last behavior session, rats (vehicle: $n=8 ; \mathrm{A} \beta: n=9)$ were anesthetized with urethane $(1.5 \mathrm{~g} / \mathrm{kg}$, i.p.) and placed in a stereotaxic frame. In addition to the general anesthesia, all incision sites and pressure points were swabbed with lidocaine before surgery. To record LFPs, wide-field monopolar electrodes were placed above the left hippocampus (AP: 5; L: 3; DV: cortical surface) and on the occipital crest as a reference, as mentioned above. The skull was opened above the medial septum-diagonal band (AP: 9.5; L: 0), and the central sinus was ligated and cut. Single units were recorded along the midline of the medial septum-diagonal band (L: $0 \pm 0.4)$ using glass microelectrodes $(10-15 \mathrm{M} \Omega$ ) filled with $0.5 \mathrm{~m}$ sodium acetate and $5 \%$ neurobiotin (Vector Laboratories). Single units were recorded in the presence of hippocampal $\theta$, either occurring spontaneously or induced by mild pressure on the tail. The neuronal signal was amplified by a DC amplifier (Axoclamp 2B; Molecular Devices), filtered between 0.1 and 5 $\mathrm{kHz}$ using a signal conditioner (Cyberamp 380; Molecular Devices), and digitized at $25 \mathrm{kHz}$ (Cambridge Electronic Design). Once a single neuron was isolated, the discharge rate and spontaneous or induced bursting activity were examined online and then recorded for $\sim 5 \mathrm{~min}$. A fraction of the recorded neurons (the nonjuxtacellular labeled neurons) from the medial septum-diagonal band was obtained from the same rats for which LFP and behavioral studies were carried out [vehicle group: four rats ( 35 cells); $A \beta$ group: five rats ( 37 cells)]. Juxtacellular recording and labeling studies were carried out to identify the neurochemistry of rhythmic bursting (RB) and slow medial septum-diagonal band neurons in a new set of animals, with the addition of one animal per group from the LFP and behavioral studies [vehicle group: 10 rats ( 14 cells); $A \beta$ group: 11 rats ( 16 cells)]. The electrode was positioned progressively closer to the targeted cell. Pulses of anode current (200 ms; 50\% duty cycle) were delivered through the neurobiotin-filled recording electrode. Current amplitude was incrementally increased from 0.4 to $15 \mathrm{nA}$ until the cell was driven to fire for 3-10 min (Pinault, 1996). When two cells were targeted in the same rat, they were located in distinct areas of the medial septum-diagonal band (left or right side, dorsal or ventral) to ensure unambiguous identification (mean number of labeled cells/rat: vehicle, $1.4 ; A \beta, 1.45)$. Only neurons located within the medial septum-diagonal band were included in this study.

Analysis was carried out for periods of $\theta$ oscillation identified by a continuous wavelet transform with Morlet wavelets, with at least $25 \%$ of the wavelet power of the $0-10 \mathrm{~Hz}$ band contained in the $3-5 \mathrm{~Hz}$ band. The average discharge rate (spikes/s) and instantaneous firing frequency $(f)$ [i.e., the first modal peak of the interspike interval histogram (ISIH; 200 bins of $5 \mathrm{~ms}$ )] were calculated, and an autocorrelation histogram (HAC; 100 bins of $10 \mathrm{~ms}$ ) was constructed to characterize the RB pattern of activity. The autocorrelation histogram shows periodic peaks of sinusoidal density with the occurrence of recurrent events such as a rhythmic burst of action potentials (Perkel et al., 1967). An "index" of rhythmic activity (average value of peaks minus average value of troughs divided by the average discharge rate) was used to classify cells as RB or non-RB neurons (Apartis et al., 1998). Cells with an index below 0.95 were classified as nonrhythmic. A higher index denotes more regular RB activity. Four patterns of discharge were distinguished: burst firing (2-20 spikes/ burst; intraburst interval: $30 \mathrm{~ms}$; interburst interval: $60 \mathrm{~ms}$; bimodal ISIH, rhythmicity index: 0.95); cluster firing (irregular clusters of a few spikes; abscissa of $(f)$ ISIH, $<25 \mathrm{~ms}$ ); tonic firing (average discharge rate, $>4$ spikes/s, ISIH monomodal; abscissa of ( $f$ ) ISIH, $>25$ ms, flat HAC) and slow firing (average discharge rate $<4$ spikes/s). In addition, the duration of the burst and the number of spikes per burst were calculated for burst analysis (20 bursts per cell).

Phase locking was assessed over the periods of $\theta$ oscillations identified previously. The phase of each spike during these periods was computed relative to the positive peaks (corresponding to the zero phase) of the $3-5 \mathrm{~Hz}$ bandpass-filtered LFP. The spike distribution of the phases was then fitted with a von Mises distribution to yield the preferential phase and phase concentration degree $(\kappa)$. All rhythmic bursting cells were found above a threshold of Kappa $>0.5$, corresponding to $>40 \%$ of the analyzed spikes preferentially locked to the $\theta$ rhythm. The goodness-of-fit was tested against the null hypothesis of uniformity by a Rayleigh test. No fit was performed when $<10$ spikes were available.

Neuroanatomy for juxtacellular labeled cells. From 1 to $6 \mathrm{~h}$ after the labeling of neurons immediately following electrophysiological recording, deeply anesthetized rats were perfused transcardially with paraformaldehyde $(4 \%)$ in $\mathrm{NaK}_{2}$ buffer $(0.1 \mathrm{M})$ with picric acid $15 \%$. Brains were cryoprotected with $30 \%$ sucrose for $24-72 \mathrm{~h}$ and then frozen at $-30^{\circ} \mathrm{C}$. They were coronally sectioned at a thickness of $40 \mu \mathrm{m}$ at the level of the medial septum-diagonal band (AP: 9.9 to 8.8) (Paxinos and Watson, 1986), and sections were collected in $0.1 \mathrm{M} \mathrm{NaK}_{2}$ buffer with sodium azide $(0.05 \%)$. For the detection of neurobiotin-injected neurons, free-floating sections were incubated with streptavidin-Cy3 (1:4000; Jackson ImmunoResearch Laboratories) in Tris-buffered saline (TBS), $\mathrm{pH} 7.4$, for $30 \mathrm{~min}$. They were then rinsed in TBS, mounted on glass slides, and coverslipped with Vectashield (Vector Laboratories). Red fluorescentlabeled cells were located with an Axioplan 2 microscope under epifluorescence illumination (Zeiss).

Immunohistochemistry: primary antibodies. Cholinergic cells were detected with a goat antiserum directed against choline acetyltransferase (ChAT) (1:100; Millipore Bioscience Research Reagents, catalog \#AB144P). GABAergic cells were detected with a polyclonal rabbit antibody that preferentially recognizes the larger form $(67 \mathrm{KDa})$ of glutamic acid decarboxylase (GAD67) but also recognizes GAD65 (1/500; Millipore Bioscience Research Reagents, catalog \#AB5992). A monoclonal antibody directed against the calcium binding protein parvalbumin (1: 500; Sigma catalog \#P3088) was also used.

To characterize the neurochemical identity of neurobiotin-containing neurons, the relevant sections were demounted, rinsed in TBS, and blocked by preincubation in 5\% normal donkey serum in TBS for 30 min. When cells were expected to be cholinergic (based on electrophysiological parameters), sections were incubated in a mixture of goat antiChAT and rabbit anti-GAD primary antibodies for $48 \mathrm{~h}$ at room temperature, and immunoreactivity was revealed with a mixture of Alexa 488-conjugated donkey anti-goat IgG (1:100; Invitrogen) and Cy5conjugated donkey anti-rabbit IgG (1:100; Jackson ImmunoResearch) for $2 \mathrm{~h}$. When cells were expected to contain parvalbumin, sections were incubated in a mixture of mouse anti-parvalbumin and rabbit anti-GAD, and immunoreactivity was detected with Alexa 488-conjugated donkey anti-mouse IgG (1:100; Invitrogen) mixed with Cy5-conjugated donkey anti-rabbit IgG. Sections were then rinsed, mounted, and coverslipped. To ensure the detection of all phenotypes, when neurobiotin-labeled cells were negative for ChAT immunolabeling, sections were reincubated for parvalbumin detection and vice versa. Control incubations performed with sections containing ectopically labeled cells included an omission of the primary antibodies to test for nonspecific binding of the secondary antibodies and incubation with one of the primary antibodies and all secondary antibodies to demonstrate the absence of cross-reactivity in double- and triple-labeling experiments. The Cy3/A488/Cy5 triplelabeled cells (neurobiotin/ChAT or parvalbumin/GAD) were detected by confocal laser scanning microscopy using a TCS SP2 confocal imaging system equipped with a $488 \mathrm{~nm}$ argon, a $543 \mathrm{~nm}$ helium-neon, and a 633 nm helium-neon laser (Leica Microsystems). Digital images were collected from a single optical plane using a $40 \times$ Plan-Apochromat oilimmersion lens (numerical aperture, 1.25). The pinhole setting was 1 Airy unit for all images. Triple-fluorescence images were acquired in sequential mode to avoid potential contamination by linkage-specific fluorescence emission cross talk.

Histology. Histology and immunohistochemistry were systematically performed to identify the injection tract, the injection site, and $\mathrm{A} \beta$ deposits. Specific antibodies were used to assess astrocytic (rabbit polyclonal anti-GFAP, 1:2000 dilution; DakoCytomation) and microglial activation (OX42, 1:100 dilution; Serotec) and the presence of the $\mathrm{A} \beta$ peptide in tissue (anti-A $\beta, 1: 200$ dilution; DakoCytomation). 4',6Diamidino-2-phenylindole (DAPI; 1:5000) was used to stain nuclei. For 
immunohistochemistry, immunolabeling was performed on freefloating $40-\mu \mathrm{m}$-thick sections. Sections were rinsed in TBS $(0.1 \mathrm{M})$ three times (10 $\mathrm{min} /$ wash). Nonspecific epitopes were then blocked by incubation in 10\% normal donkey serum and $0.3 \%$ Triton X-100 in TBS for $1 \mathrm{~h}$. Sections were incubated in the primary antibodies overnight at room temperature and washed again three times in TBS (10 min/wash). Secondary antibodies (donkey anti-rabbit $\mathrm{Cy} 3$ and donkey anti-mouse Alexa 488, 1:200 dilution) were applied for $90 \mathrm{~min}$. DAPI (1:10 $\left.{ }^{7}\right)$ was added $5 \mathrm{~min}$ before the end of staining. All sections were mounted on Superfrost slides with Fluoromount and coverslipped. Cells were visualized with a Zeiss Axioplan 2 microscope under epifluorescence illumination. Control incubations performed using adjacent sections included an omission of the primary antibodies to test for nonspecific binding by the secondary antibodies.

Cell counting and immunoreactivity. To estimate the loss of cells in the medial septum-diagonal band, ChAT, parvalbumin, and NeuN (neuronal marker) labeling was performed on 5 medial septum-diagonal band sections $(40 \mu \mathrm{m})$ from a separate experimental set of five vehicle- and five $\mathrm{A} \beta$-injected rats. These sections corresponded to the major part of the vertical limb $\left(0.6 \mathrm{~mm}^{2}\right.$ fields, $>60 \%$ of medial septum-diagonal band between levels 9.7 and 9.3 anterior to the interaural level). Immunolabeled somata were analyzed using the free NIH ImageJ (version 1.40) software and independently counted by two individuals blind to the experimental protocol. Data from five slices were expressed as a percentage of the mean value obtained for vehicle-treated animals. For the identification of microglia, $40 \mu \mathrm{m}$ slices from the dorsal hippocampus, spaced $160 \mu \mathrm{m}$ apart, were labeled with the mouse anti-OX42 antibody and revealed using donkey anti-mouse Alexa 488. Images of the reaction site were acquired using a $10 \times$ objective with a Photometrics camera under epifluorescence illumination. The sum of the mean fluorescence in the $x$-axis of each picture (examples in supplemental Fig. S1C, available at www.jneurosci.org) was calculated and the spectrum was integrated using the NIH ImageJ (version 1.40) software. The spectra of eight slices per hippocampus and per rat were summed (vehicle, $n=7 ; \mathrm{A} \beta, n=9$ ). The relative level of $\mathrm{A} \beta$ immunolabeling measured in $\mathrm{A} \beta$-injected animals (mean \pm SEM) was compared with immunolabeling in vehicle-treated animals.

Statistical analysis. Behavioral and electrophysiological data (LFP power and frequency) were analyzed using repeated measures ANOVA with trial and group as factors and regression during the course of learning. Follow-up comparisons between groups during specific days or measures of cell density were analyzed using an unpaired $t$ test. Neuronal populations and electrophysiological classes were analyzed using a $\chi^{2}$ test.

\section{Results}

\section{Hippocampal A $\beta$ injections induce progressive impairment} of recognition memory and $\theta$ rhythm power

Multiple bilateral microinjections of $A \beta 40$ and $A \beta 42$ into the dorsal hippocampus (see Materials and Methods) were carried out to obtain long-lasting focal A $\beta$ deposits and neuroinflammation as reported previously (Stéphan et al., 2001, 2003) (supplemental Fig. S1, available at www.jneurosci.org). To test whether $\mathrm{A} \beta$ injections induce changes in visuospatial recognition memory performance, the exploratory behavior of rats with respect to familiar and novel items was monitored from the day before to $21 \mathrm{~d}$ after the microinjection of $\mathrm{A} \beta$ or vehicle. As shown in supplemental Figure S2, $A$ and $B$, available at www.jneurosci.org, $\mathrm{A} \beta$ - and vehicle-treated rats did not differ with respect to the total number of items explored during the 5 min sessions, with 8-22 spontaneous visits for each group [repeated measures ANOVA with group and day as factors; training trials: $F_{(1,14)}=0.46$, not significant (ns); test trials: $\left.F_{(1,14)}=0.37, \mathrm{~ns}\right]$. Neither did the two groups of rats differ in terms of the time spent to complete each movement pattern, i.e., initiation of climbing, climbing, rearing and contact with the stimulus, and descent (D21, unpaired $t$ test; initiation of climbing: $t_{(1-12)}=0.927$, ns; climbing: $t_{(1-12)}=$
$0.566, \mathrm{~ns}$; rearing and contact with stimulus: $t_{(1-12)}=-0.549, \mathrm{~ns}$; and descent: $t_{(1-12)}=0.373$, ns) (supplemental Fig. S2C,D, available at www.jneurosci.org). In contrast, $\mathrm{A} \beta$ - and vehicle-treated rats differed in terms of item preference across test sessions (Fig. $1 B, C)$. Vehicle-treated rats presented a progressive decrease in expression of activity to familiar items and positions $(n=7$, linear regression analysis with day as the independent factor and activity as the dependent factor, LT: $\left.F_{(1,89)}=9,7, p<0.05\right)$ and a reciprocal increase in activity related to novel items and positions across test trials (linear regression analysis, NS: $F_{(1,89)}=$ 4,27, $p<0.05)$. In contrast, $\mathrm{A} \beta$-treated rats spent more time exploring familiar items and positions $\left(n=9\right.$; LT: $F_{(1,115)}=$ $15,77, p<0.05)$ and progressively decreased their exploratory activity related to new items and positions (NS: $F_{(1,115)}=8,43$, $p<0.05$ ), an effect that was exacerbated during the third week after the injections (Fig. $1 B, C$ ). The interaction between groups and time (sessions) (ANOVA repeated measures, LT items: $\left.F_{(12,168)}=3.22, p<0.01\right)$ indicated that hippocampal $\mathrm{A} \beta$ treatment induces a progressive deficit over time in the ability to discriminate between previously explored items and novel ones.

Since empirical studies have demonstrated the involvement of hippocampal $\theta$ oscillations in memory encoding and retrieval processes (Sederberg et al., 2003; McCartney et al., 2004; Ekstrom et al., 2005; Mormann et al., 2005), $\theta$ oscillations from hippocampal fields were recorded during item exploration. LFP episodes during basal exploration $(\mathrm{D}-1)$ were similar in $\mathrm{A} \beta$ - and vehicletreated rats in terms of oscillatory activity (data not shown), but lower $\theta$ power activity during $\theta$ LFP episodes was observed $21 \mathrm{~d}$ after $\mathrm{A} \beta$ injections (Fig. $1 D, E$ ). To analyze the time course of oscillatory changes, normalized $\theta$ power from LFP epochs during exploratory behavior were averaged by group and session (see Materials and Methods) (Fig. $1 F, G$ ). The power in frequencies below the $\theta$ band was comparable between vehicle-treated $(n=$ $8)$ and $\mathrm{A} \beta$-treated rats $(n=9)(\mathrm{D} 21,14$ and $15.5 \%$ respectively; repeated measures ANOVA with group and time as factors: $F_{(15,180)}=1.595$, ns). The $\theta$ power of vehicle-treated rats was stable over time, while it markedly decreased between D9 and D21 in A $\beta$-treated rats (from 68.5 to $60.5 \%$; repeated measures ANOVA with group and time as factors: $F_{(15,180)}=2.787, p<$ $0.01)$. In $A \beta$-treated rats, the power of higher frequency activity progressively increased from D9 to D21 (15.3 to 20.8\%), but not in vehicle-treated rats (15.7 to $15.2 \%$, repeated measures ANOVA with group and time as factors: $F_{(15,180)}=3.98, p<$ 0.0001) (Fig. 1G).

To understand whether the $\theta$ alteration was directly related to the $A \beta$ treatment independently of learning differences per se, data were obtained from an additional set of rats $[\mathrm{A} \beta(n=4)$ or vehicle $(n=3)]$ that were exposed to the same experimental context except for the omission of the stimuli, i.e., they had no stimuli recognition learning to achieve (Fig. $1 H$; supplemental Fig. S2 $E$, available at www.jneurosci.org). In these $A \beta$-treated rats without stimuli presentation, $\theta$ activity also declined with time while such decline did not occur in vehicle-injected rats [time effect on $\theta$ activity with treatment ( $\mathrm{A} \beta$ vs vehicle) by repeated measures ANOVA, group and time factors: $F_{(1,12)}=$ $2.039, p<0.01]$. Finally, a decrease in absolute $\theta$ power 3 weeks after injection was observed in $\mathrm{A} \beta$-treated rats, but not in vehicletreated rats (ANOVA: $F_{(1,15)}=0.033, p<0.05$ ) (supplemental Fig. S2 F, available at www.jneurosci.org). Thus, $A \beta$ injections in the dorsal hippocampus induced a progressive decrease in hippocampal $\theta$ oscillations that correlated with behavioral shift toward familiar stimuli. 
A

Vehicle

D21

New

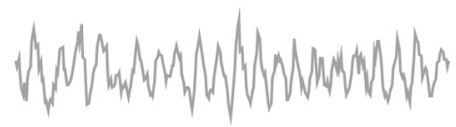

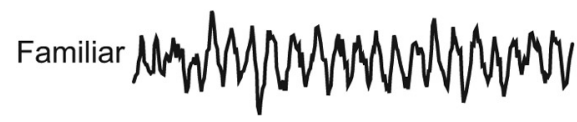

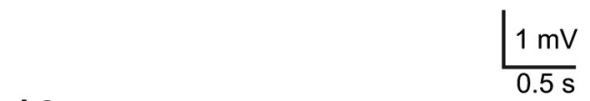

$\mathrm{A} \beta$

New

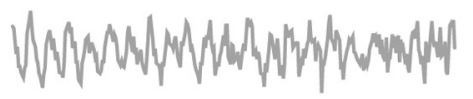

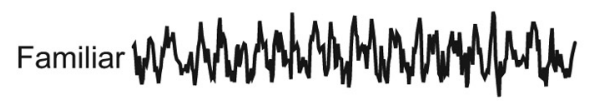

B
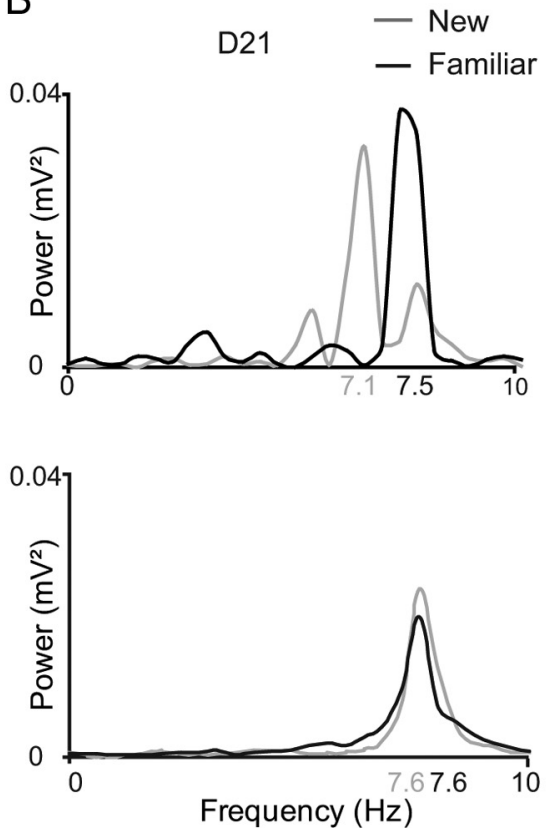

C

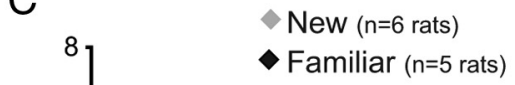

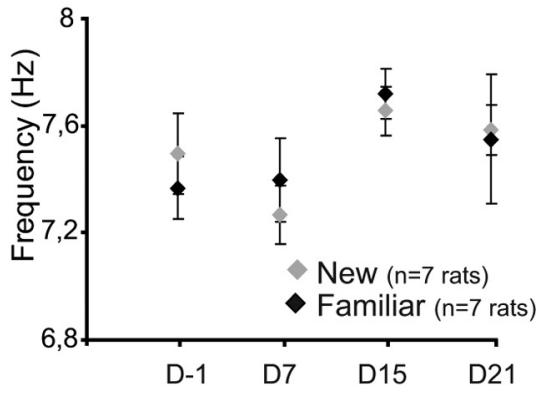

Figure 2. Loss of task-related $\theta$ frequency modulation after hippocampal A $\beta$ injection. $A$, Examples of raw LFP ( 3 s epochs) for vehicle-treated (top) and A $\beta$-treated animals (bottom) during exploration of familiar (black line) and new (gray line) items, on the 21st day after the injections. $\boldsymbol{B}$, Averaged power spectra in the $0-10 \mathrm{~Hz}$ band, analyzed from LFP epochs during exploration of familiar or new items on the 21st day after the injections. C, Progressive evolution of peak power spectrum frequency during exploration of familiar (black diamond) or new (gray diamond) items for vehicle-treated (top) and $A \beta$-treated animals (bottom) $\left(n=8\right.$ to 12 sequences per class). Data are represented as mean $\pm S E M,{ }^{*} p<0.05$; ANOVA with group and day as factors. $\theta$ frequency is modulated by novelty in vehicle but not in $A \beta$-treated animals.

\section{Hippocampal A $\beta$ injections alter the frequency modulation associated with recognition memory}

A link between novelty detection and hippocampal $\theta$ rhythm has recently been established by the demonstration of a drop in the peak frequency of $\theta$ during exposure to environmental novelty (Burgess et al., 2007; Jeewajee et al., 2008). In vehicle-treated rats, the analysis of LFP epochs during the exploration of novel and familiar items revealed that the peak $\theta$ frequency changed according to the novelty of the items visited (Fig. $2 A, B$ ). The peak $\theta$ frequency dropped on days 15 and 21, when vehicle-treated rats expressed behavioral discrimination between new and familiar items (unpaired $t$ test; $\mathrm{D}-1: t_{(1-15)}=-0.41$, ns; D15: $t_{(1-23)}=2.31, p<0.05$; D21: $\left.t_{(1-23)}=2.31, p<0.05\right)($ Fig. $2 C)$. In contrast, $A \beta$-treated rats failed to exhibit a modulation of the peak $\theta$ frequency during the exploration of novel items (Fig. $2 C)\left(\mathrm{D}-1: t_{(1-31)}=-0.32\right.$, ns; D15: $t_{(1-24)}=0.63$, ns; D21: $\left.t_{(1-23)}=-0.021, \mathrm{~ns}\right)$.

To control for any potential effects of running speed on the analysis of frequency modulation according to novelty detection (Jeewajee et al., 2008), behavioral variables such as the total distance traveled, average positive speed, and acceleration during the test session were analyzed on day 21 , when vehicle-treated rats exhibited a drop in $\theta$ frequency in correlation with behavioral discrimination between novel and familiar stimuli (supplemental Fig. S3, available at www.jneurosci.org). Differences in total distance traveled $\left(t_{(1-12)}=0.68\right.$, ns) (supplemental Fig .S3 $A, B$, available at www.jneurosci.org), average non-null speed on running epochs $\left(t_{(1-12)}=1.47, \mathrm{~ns}\right)$, and average positive acceleration $\left(t_{(1-12)}=1.11, \mathrm{~ns}\right)$ between groups were nonsignificant, as revealed by unpaired $t$ tests.

Because $\theta$ oscillations are involved in mechanisms underlying sensorimotor integration (Bland and Oddie, 2001), the dynamic oscillation frequencies were further explored during different behavioral phases, i.e., before, during, and after item exploration (supplemental Fig. S4, available at www.jneurosci.org). Averaged time-frequency maps and cumulative proportion of frequencies were obtained from a larger $\theta$ band $(4-10 \mathrm{~Hz})$ on the LFP collected $21 \mathrm{~d}$ after injections. In vehicle-treated rats, a modulation of the frequency of the $\theta$ oscillations took place during the different behavioral phases with lower $\theta$ oscillations before and after stimuli exploration. In contrast, in $\mathrm{A} \beta$-treated rats no modulation of the frequency was observed across the behavioral phases, and $\theta$ oscillations tended to higher frequency (supplemental Fig. $\mathrm{S} 4 E$, available at www.jneurosci.org).

Altogether, the behavioral data demonstrate reduced $\theta$ band oscillation modulation in response to the familiarity/novelty context in $\mathrm{A} \beta$-treated rats.

\section{Hippocampal $\mathrm{A} \boldsymbol{\beta}$ injections reduce the activity of rhythmic GABAergic neurons in the medial septum-diagonal band of Broca}

Intact septohippocampal projections are required for the generation of the hippocampal $\theta$ rhythm (for review, see Buzsáki, 2002). To assess whether hippocampal $A \beta$ infusions alter neuronal activity in the septohippocampal network, medial septumdiagonal band neurons were recorded under anesthesia during hippocampal $\theta$ epochs, 25 ( \pm 3 ) days after $\mathrm{A} \beta$ or vehicle injections. All neurons presented specific firing patterns during the hippocampal $\theta$ rhythm (Sotty et al., 2003; Borhegyi et al., 2004; Simon et al., 2006): "slow" cells that on average fired less than one spike per $\theta$ cycle, "tonic" cells that on average fired more than one spike per $\theta$ cycle but did not fire bursts, and "rhythmic bursting" cells, which are known to be GABAergic septohippocampal neurons, and that fired bursts of spikes phase locked to the $\theta$ cycle (Fig. $3 A, B$ ). A small fraction of the recorded cells (vehicle: $n=$ 6/49; $\mathrm{A} \beta: n=7 / 53$ ) exhibited bursting activity intermingled with long pauses (supplemental Fig. S5, available at www.jneurosci. org as supplemental material) previously described as "cluster- 
A

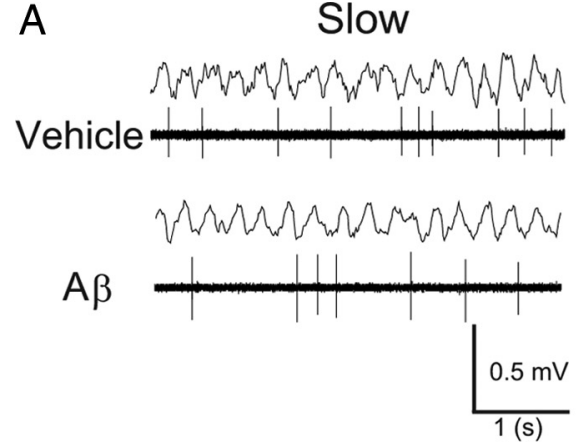

B

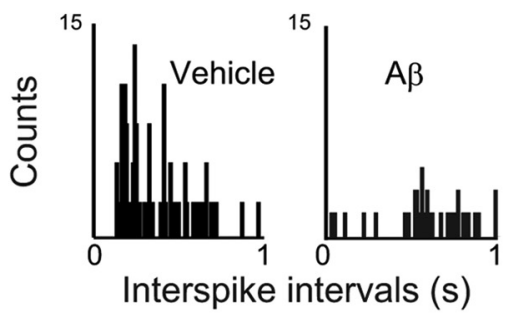

Rhythmic
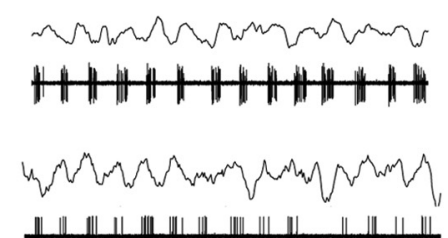

$2 \mathrm{mV}$

1 (s)
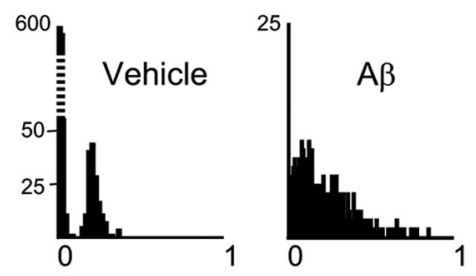

Tonic

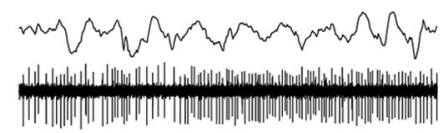

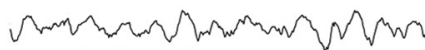

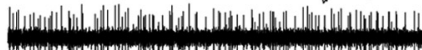

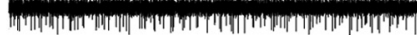

$0.5 \mathrm{mV}$

1 (s)

C

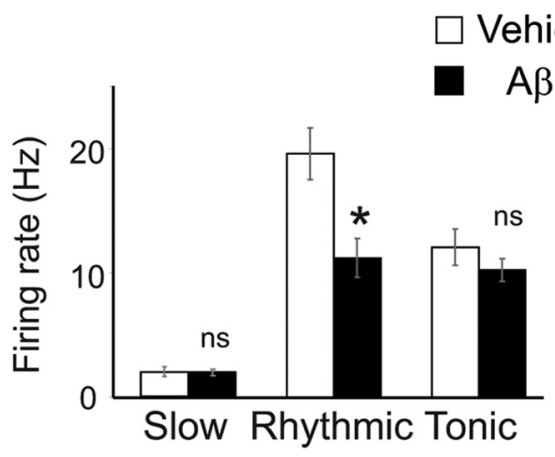

D

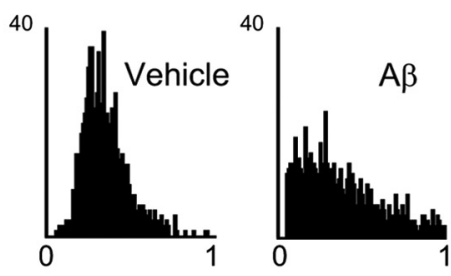

Rhythmic Bursts

Vehicle

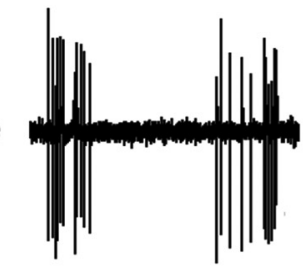

$A \beta$

$\frac{0.15 \mathrm{mV}}{0.1(\mathrm{~s})}$

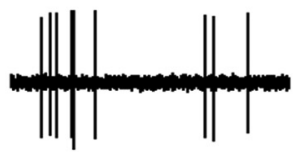

Figure 3. Decreased rhythmic bursting activity in medial septal neurons after hippocampal $A \beta$ injection. $A$, Examples of medial septal neurons electrophysiologically classified as slow, rhythmic, or tonic for vehicle- and A $\beta$-treated animals during hippocampal $\theta$ epochs (top traces). $B$, Corresponding interspike interval histograms for each class of cells in vehicle-treated (left-hand graph for each cell type) and A $\beta$-treated animals (right-hand graph for each cell type). C, Mean spontaneous firing rate for each class of medial septal neurons from vehicle-treated (white bars, $n=49$ ) and $\mathrm{A} \beta$-treated animals (black bars, $n=53$ ); ${ }^{*} p<0.05$, ANOVA with group and cell class as factors. $D$, Examples of rhythmic bursts in rhythmic neurons from vehicle-treated (left) and A $\beta$-treated animals (right). The rhythmic bursting activity in medial septal neurons is specifically altered in $A \beta$-treated rats.

type" activity (Simon et al., 2006). No difference was seen between such cells from vehicle- and $\mathrm{A} \beta$-treated animals, and they were not given further consideration in the present study (supplemental Fig. S5, available at www.jneurosci.org). A $\beta$ injections did not alter the average firing rate of slow-firing and tonicfiring septal neurons during $\theta$ oscillation; in contrast, rhythmic bursting neurons exhibited a $\sim 40 \%$ reduction in the firing rate after $\mathrm{A} \beta$ injection (Fig. $3 C$ ). Moreover, these cells exhibited a nonsignificant trend for shorter burst with $20 \%$ decrease in duration (vehicle: $98.8 \mathrm{~ms} ; \mathrm{A} \beta: 78.8 \mathrm{~ms}$ ) and a $40 \%$ decrease of spike number per burst [vehicle $(n=10$ cells $): 6.5 \pm 0.46$ spikes/burst; $\mathrm{A} \beta(n=10$ cells $): 4.0 \pm 0.39$ spikes/burst; $t$ test $F_{(1,18)}=4075, p<0.05$ ) (for examples, see Fig. $3 D$ ). Thus, hippocampal $\mathrm{A} \beta$ injections resulted in the specific reduction of firing activity in rhythmic bursting medial septum-diagonal band neuron.

Hippocampal A $\beta$ injections increased the occurrence of $\theta$ phase-locked slow-firing neurons

The firing of a large percentage of septal neurons is modulated in phase with hippocampal $\theta$ oscillations (Gogolák et al., 1968). An analysis of this phase locking of septal neurons to $\theta$ oscillations also revealed changes following $\mathrm{A} \beta$ injection. The occurrence of phase-locking was assessed by a Rayleigh test (see Materials and Methods and supplemental Fig. S6, available at www.jneurosci. org). Its magnitude was quantified by fitting it with a von Mises distribution, which yielded a value for the concentration of the distribution, $\kappa$, indicating the degree of phase locking (with a higher $\kappa$ corresponding to stronger phase locking) (for examples, see Fig. $4 A, B, C$ for slow, rhythmic, and tonic cells, respectively). Among phase-locked neurons in the vehicle group, the vast majority, i.e., 17/19 cells, presented rhythmic bursting activity (Fig. $4 B, D, E)$, whereas only two phase-locked cells displayed slow activity (Fig. $4 E$ ). In marked contrast, in $\mathrm{A} \beta$-injected animals a significantly higher proportion of $\theta$ phase-locked cells displayed a slow-firing pattern (8/21 cells) (binomial test, $p<0.05$ ) (Fig. $4 A, D, E)$. This suggested that $\mathrm{A} \beta$ injections reduced the firing rate of some rhythmic bursting neurons to less than one spike per $\theta$ cycle but did not interfere with their phase locking to $\theta$. To assess the relation between reduced firing rate and decreased $\theta$ power, a correlative analysis was performed. Lower firing rate of phase locked unit cells significantly correlated with the decrease of $\theta$ power record $\left(F_{(1,20)}=12.52, R^{2}=0.3851, p<0.005\right.$; data not shown). 
Neurochemical identification of slow and rhythmic firing septal neurons after hippocampal $A \boldsymbol{\beta}$ injection

To investigate changes in the properties of septal neurons, electrophysiological recordings were combined with juxtacellular labeling followed by immunohistochemistry (29 cells). The recorded neurons were located in the vertical limb of the medial septum (supplemental Fig. S7, available at www. jneurosci.org). Almost all rhythmic bursting neurons ( $8 / 9$ and 9/9 in vehicle- and $\mathrm{A} \beta$-injected rats, respectively; no immunoreactivity was seen in one rhythmic bursting neuron) exhibited the expected GABAergic phenotype (for examples, see Fig. $5 A, B)$. Among these, a third (3/9 and $3 / 9$ in vehicle- and $A \beta$-treated rats) were both parvalbumin and GABA immunoreactive, in agreement with the proportion of such cells reported previously (Sotty et al., 2003; Borhegyi et al., 2004; Simon et al., 2006) (for examples, see Fig. 5A). In $\mathrm{A} \beta$-treated rats, parvalbumin-expressing GABAergic neurons displayed a significantly lower firing rate than those recorded in vehicle-treated rats (mean firing rate, $22.18 \pm 4.23$ and $9.81 \pm 2.78 \mathrm{~Hz}$ from vehicle- and $\mathrm{A} \beta$-treated rats, respectively; unpaired $t$ test, $p<0.05$; see supplemental Table 1, available at www.jneurosci.org) (for examples, see Fig. $5 B$ ). In contrast, the difference did not reach significance in GABAergic neurons that did not express parvalbumin (vehicle: $n=5$ cells, mean firing rate, $23.96 \pm 5.05 \mathrm{~Hz} ; \mathrm{A} \beta$-treated rats: $n=6$ cells, mean firing rate, $13.41 \pm 3.07$ $\mathrm{Hz}$; unpaired $t$ test, ns). All parvalbuminpositive GABAergic rhythmic bursting neurons from vehicle- and $A \beta$ treated animals were similarly phase locked to $\theta$. Thus, $\mathrm{A} \beta$ injections preferentially reduced the firing rate of parvalbumin-expressing GABAergic rhythmic bursting neurons, which are known to be septohippocampal projection neurons (Tóth et al., 1993).

Slow-firing neurons were labeled during recordings in vehicle-treated $(n=6)$ and $\mathrm{A} \beta$ treated rats $(n=6)$ (see supplemental Table 1, available at www. jneurosci.org as supplemental material; for example, see Fig. $5 C, D)$. In vehicle-treated rats, two cells were GABAergic, one was cholinergic, and three were neither cholinergic nor GABAergic. In $A \beta$-treated rats, five of the six neurons expressed a GABAergic phenotype while the remaining cell was neither cholinergic nor GABAergic (for example, see Fig. $5 C, D$ ). Thus, in $\mathrm{A} \beta$-treated rats the slow-firing neuronal population mostly consisted of GABAergic cells, whereas these cells constituted only a minority of the population in vehicle-treated rats as previously observed in noninjected animals (Simon et al., 2006).

We next investigated whether the absence of cholinergic cells in our example from $\mathrm{A} \beta$-treated rats was due to a strong cholinergic depletion in the septum-diagonal band. However, when

\section{B Rhythmic neuron}

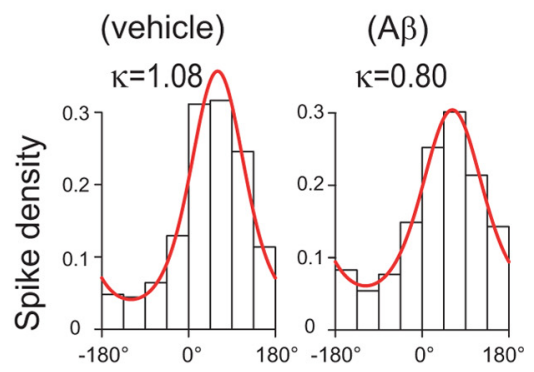

$\mathrm{D}$

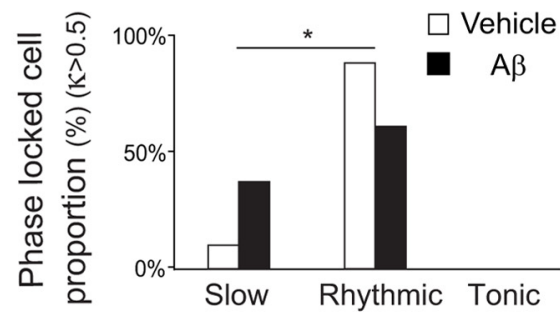

$(\mathrm{A} \beta)$
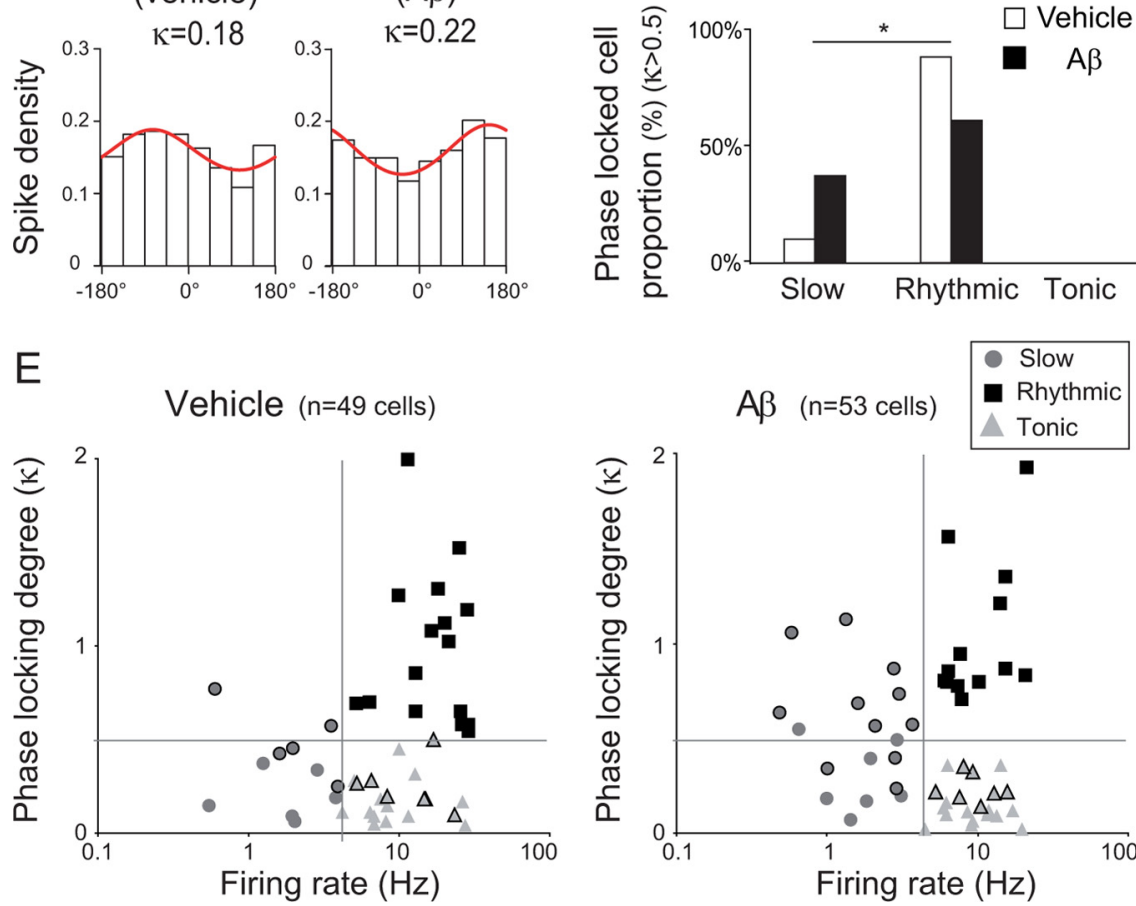

Figure 4. Increased occurrence of $\theta$ phase-locked slow neurons after hippocampal $A \beta$ injection. $\boldsymbol{A}-\boldsymbol{C}$, Examples of spike distribution within the $\theta$ cycle for slow $(\boldsymbol{A})$, rhythmic $(\boldsymbol{B})$, and tonic $(\boldsymbol{C})$ neurons. The phase distribution of spikes was fitted with a von Mises distribution and its concentration parameter $(\kappa)$ provides a quantitative measure of the phase-locking. The goodnessof fit was tested against the null hypothesis of uniformity by a Rayleigh test. $\boldsymbol{D}$, Histogram of the distribution into class of phase-locked medial septal neurons (Rayleigh test, $p<0.05$ and $\kappa>0.5$ ) from vehicle (white bar; total phase-locked neurons, $n=19$ ) and $A \beta$-treated animals (black bar; total phase-locked neurons, $n=21$ ). ${ }^{*} p<0.05 ; \chi^{2}$ test for population variance (light panel). Cells with a black outline are the cells with $p<0.05$ in the test for uniformity. Light gray triangles, Tonic-firing cells; dark gray circles, slow-firing cells; black squares, rhythmic firing cells. The number of medial septum slow-firing neurons that are phase-correlated to $\theta$ waves increased in $A \beta$-treated rats.

compared to vehicle-treated rats the decrease in ChAT cell density and immunoreactivity in $\mathrm{A} \beta$-treated rats was surprisingly minimal $(-14$ and $-16 \%$, respectively) and nonsignificant (unpaired $t$ test, ns) (Fig. $5 F)$. We also examined whether hippocampal $\mathrm{A} \beta$ injections induced the loss of GABAergic parvalbumin-expressing neurons in the medial septum-diagonal band. Paradoxically, parvalbumin immunoreactivity was increased in $\mathrm{A} \beta$-treated rats when compared to vehicle-treated animals ( $46 \%$ increase, unpaired $t$ test, $p<0.05$ ) (Fig. $5 G$ ). However, there was no modification in the total number of medial septum-diagonal band neurons labeled by the neuronspecific nuclear protein (NeuN; data not shown). These data suggest that hippocampal $A \beta$ injections did not affect the survival of parvalbumin-expressing GABAergic medial septum-diagonal band 
A
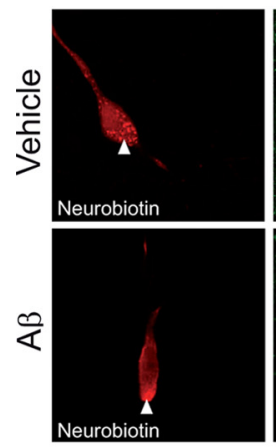

C

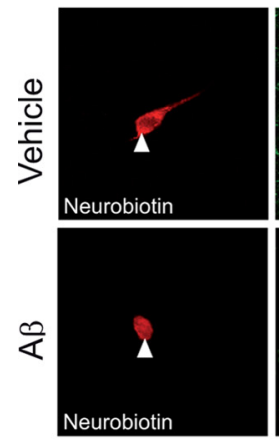

E
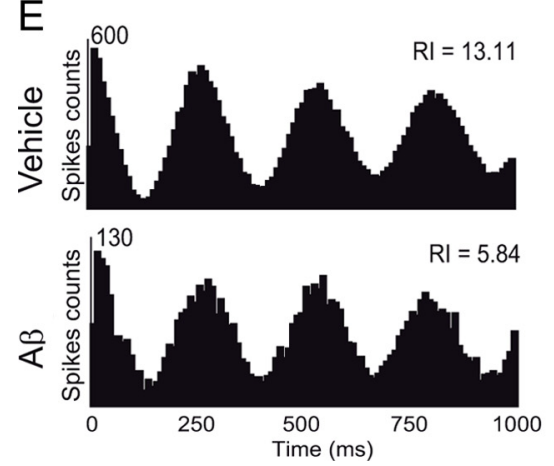

Rhythmic firing neurons
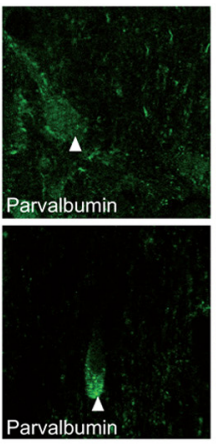

Slow firing neurons
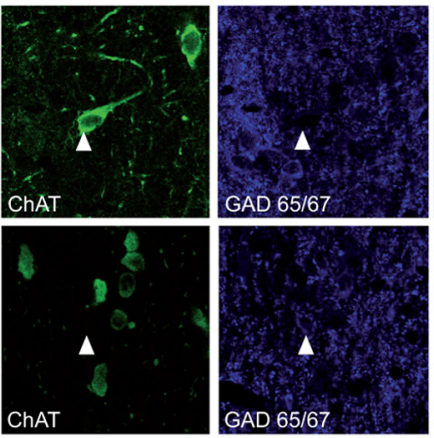

$\mathrm{F}$
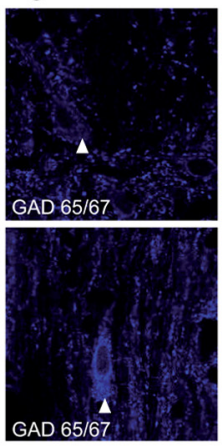
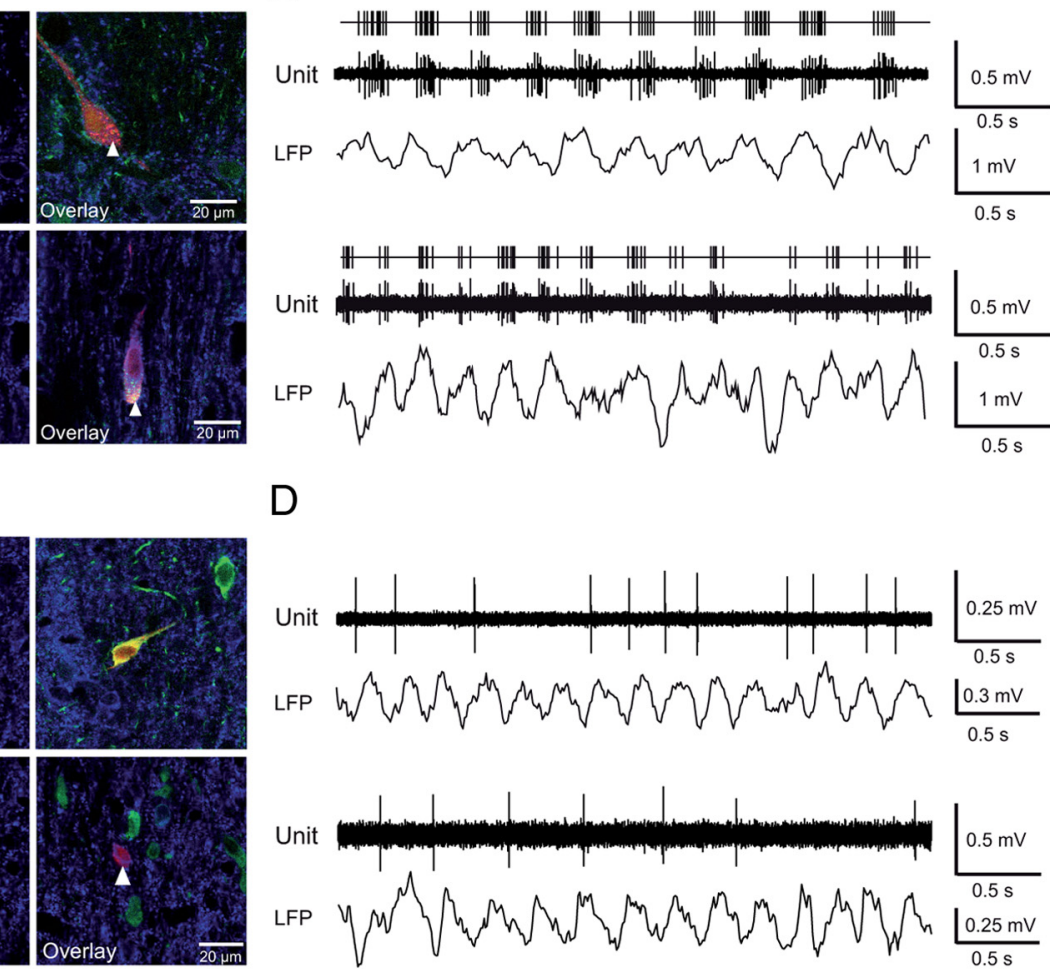

G

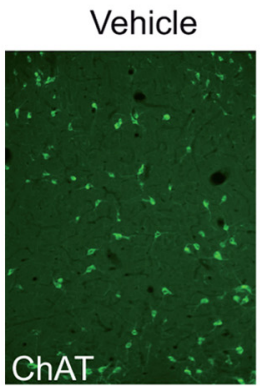

B
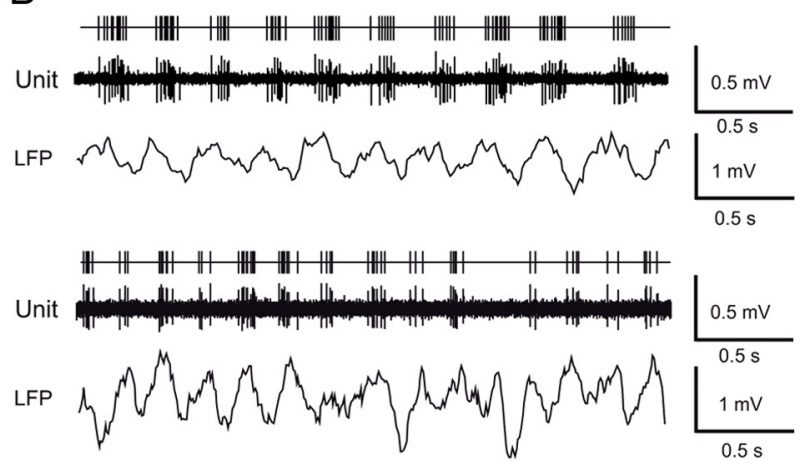

D

$\mathrm{A} \beta$

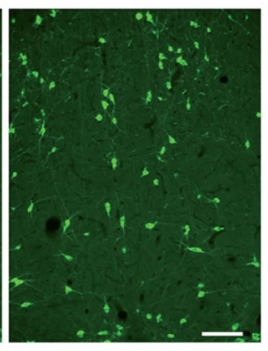

$A \beta$

Figure 5. Neurochemical identification of slow and rhythmic firing septal neurons after hippocampal injections. $\boldsymbol{A}, \boldsymbol{C}$, Examples of juxtacellular labeling in vivo under anesthesia of rhythmic $(\boldsymbol{A})$ and slow $(\boldsymbol{C})$ firing septal neurons from vehicle (top) and $A \beta$-treated (bottom) rats that were recorded during $\theta$ hippocampal activity, identified by neurobiotin staining, and counterstained for $C h A T$ and GAD. $\boldsymbol{A}$, two rhythmic GABAergic parvalbumin-positive neurons. $\boldsymbol{C}$, A cholinergic neuron in a vehicle-treated rat and a GABAergic neuron in one A $\beta$-treated rat. Scale bars, $20 \mu \mathrm{m}$. $\boldsymbol{B}, \boldsymbol{D}$, Corresponding spike activity and hippocampal LFP epochs. $\boldsymbol{E}$, Histograms of autocorrelation of B traces with the corresponding rhythmicity index (RI) (see Materials and Methods). $\boldsymbol{F}$, ChAT immunoreactivity in the medial septum after hippocampal $A \beta$ injection. Shown is an example of analyzed sections of the medial septum-diagonal band corresponding to the major part of the vertical limb $\left(0.6 \mathrm{~mm}^{2}\right.$ fields, $>60 \%$ of medial septum-diagonal band between level 9.7 and 9.3 anterior to the interaural level) from vehicle-treated (left) and $A \beta$-treated rats (right). Scale bar, $200 \mu \mathrm{m}$. G, Parvalbumin immunoreactivity in the medial septum from vehicle-treated (left) and A $\beta$-treated rats (right). Scale bar, $200 \mu \mathrm{m}$. Hippocampal A $\beta$ injections induced a reduction in GABAergic cell rhythmic firing rate and an increase in the probability for slow-firing cells to display GAD immunoreactivity in the absence of cell loss in the medial septum (see also supplemental Table 1, available at www.jneurosci.org as supplemental material).

neurons but did selectively reduce their activity while inducing an increase in parvalbumin expression.

\section{Discussion}

Despite the vulnerability of the septohippocampal system during the course of $\mathrm{AD}$, few studies have investigated how the disease affects the role of septohippocampal networks in the generation and modulation of the $\theta$ rhythm. We report here that multiple focal $\mathrm{A} \beta$ injections associated with neuroinflammatory processes in the dorsal hippocampus weaken and detune $\theta$ oscillatory activity in the dorsal hippocampus of rats during recognition memory recall. $\mathrm{A} \beta$ also specifically reduces the activity of the rhythmic bursting medial septum-diagonal band GABAergic neurons that are phase locked to $\theta$.

The present study confirms the finding that hippocampal $\mathrm{A} \beta$ injections induce a significant impairment of long term memory ability in rats (Stéphan et al., 2001; Stepanichev et al., 2006). The behavior of rats was characterized during the exploration of familiar and novel visuospatial items. The preferential exploration of novel items in this paradigm involves a comparator function between what is expected, based on retrieval of past experience, and current sensory input, an operation requiring intact hippocampal function (Hasselmo et al., 1996; Fyhn et al., 2002; Lenck-Santini et al., 2005; Kumaran and Maguire, 2006). The 
present data indicate that hippocampal $\mathrm{A} \beta$ has a major effect on visuospatial recognition memory in rats. This is consistent with the impairment in the detection of position changes observed in mouse model of AD with age (Hale and Good, 2005). While $\mathrm{A} \beta$-treated rats presented a progressive impairment in novel visuospatial exploration, they also displayed a progressive increase in exploratory behavior related to familiar items. This latter observation supports the notion that hippocampal $\mathrm{A} \beta$ injections induce behavioral perseverance or impairment in the ability to inhibit irrelevant exploratory behavior in rats. Behavioral perseverance has been linked to injury in the hippocampal system (Whishaw and Tomie, 1997; Arkhipov et al., 2008) but is even more closely associated with injury of the prefrontal cortex (Morgan et al., 2003; Clarke et al., 2004), where some neurons fire in synchrony with the hippocampal $\theta$ rhythm during learning (Jones and Wilson, 2005; Siapas et al., 2005; Sirota et al., 2008; Peyrache et al., 2009).

Theta oscillations are the main oscillations observed in the hippocampus during exploratory behavior and cognitive operations (Winson, 1978, Buzsáki and Draguhn, 2004; Manns et al., 2007). To investigate the effects of hippocampal $A \beta$ on $\theta$ oscillations, hippocampal LFPs were recorded during exploratory behavior. In vehicle-treated as in $\mathrm{A} \beta$-treated rats, $\theta$ oscillations were maximal as the rat initiated active behavior such as climbing on items. After $\mathrm{A} \beta$-injection, $\theta$ oscillations during these time periods became progressively weaker with no decrease in sensorimotor activity, indicating a progressive reduction in the LFP response to exposure to novelty. The parallel decrease in $\theta$ power and preferential visits to novel items after $\mathrm{A} \beta$-injection is consistent with the extensive literature regarding the concomitant reduction of the hippocampal $\theta$ rhythm and spatial memory performance (Chrobak et al., 1989; Brioni et al., 1990; Givens and Olton, 1990; Chrobak and Napier, 1992; Nagahara and McGaugh, 1992). The absence of a shift in the peak frequency of $\theta$, recently associated with novelty detection (Jeewajee et al., 2008) in $A \beta$ treated rats, indicates that hippocampal $\mathrm{A} \beta$ treatment disrupts the recruitment and modulation of $\theta$ oscillations in response to an increased cognitive load. This alteration is likely to play a role in the memory deficits observed in $\mathrm{AD}$, since novelty detection, which contributes to the encoding of events in memory, is a prerequisite for efficient recognition memory function. The present study provides evidence that amyloid pathology results in $\theta$ oscillations and memory alterations but does not exclude the possibility that other mechanisms also contribute to novelty detection deficits. Among them, not only $\theta$ oscillators but higher frequency activity, as gamma oscillations, could be affected by hippocampal damage. The gamma band is phase modulated by $\theta$ oscillations (Hyman et al., 2005; Siapas et al., 2005, Canolty et al., 2006; Sirota et al., 2008), and theta-gamma interactions were recently related to memory processing (Tort et al., 2009). Moreover, hippocampal high frequency oscillations, which elicit sharp waves that are good candidates for memory consolidation mechanisms (Peyrache et al., 2009, Ramadan et al., 2009), could be damaged after hippocampal amyloid injury.

It is generally assumed that the role of $\theta$ oscillations in learning processes is sustained by the imposition of a rhythmic $\theta$-paced inhibition on all pyramidal neurons in the hippocampus. This process implies a wide distribution of connections from the source of the rhythm, notably from the medial septum-diagonal band (Petsche et al., 1962; Vanderwolf, 1969, Bullock et al., 1990; Tóth et al., 1997). Long-range cholinergic (Bassant et al., 1998) and GABAergic (Tóth et al., 1993) septohippocampal projection neurons participate in the $\theta$ synchronization of hippocampal cell assemblies (Borhegyi et al., 2004). Among them, a population of parvalbumin-containing GABAergic neurons has been identified as consisting of rhythmically bursting cells (Sotty et al., 2003; Borhegyi et al., 2004; Bassant et al., 2005) that serve as pacemakers for hippocampal $\theta$ (Hangya et al., 2009). In the present study, recordings and histochemical identification indicate that hippocampal $\mathrm{A} \beta$ injections induced a decrease in the bursting activity of these neurons, but no change in their proportion or their phase-locking to $\theta$. This suggests that the $\mathrm{A} \beta$ injections did not interfere with septal $\theta$ generation but greatly weakened its transmission to the hippocampus via the activity of rhythmic bursting neurons. Indeed slow-firing neurons in $A \beta$-injected rats were essentially GABAergic, a phenomenon that is not observed in naive rats (Griffith and Matthews, 1986; Gorelova and Reiner, 1996; Sotty et al., 2003; Simon et al., 2006). Moreover, the increased proportion of $\theta$ phase-locked septal neurons that exhibit slow-firing activity in $\mathrm{A} \beta$-injected animals further indicates that hippocampal A $\beta$ strongly reduces the $\theta$-bursting activity of septohippocampal GABAergic neurons. This reduction might reflect that some GABAergic cells spilled out from rhythmic bursting class to the slow-firing neuron class. However, the preferred phase might have also changed, which then may indicate altered hippocamposeptal back projection. This would have to be investigated on a large sample of neurons, as reported for the HCN (hperpolarization-activated, cyclic nucleotide-gated nonselective cation)-expressing GABAergic cells of the medial septum (Varga et al., 2008).

Since GABAergic septohippocampal projections contact hippocampal interneurons that in turn relay phasic disinhibition to the principal neurons (Tóth et al., 1997), this reduced GABAergic input to the hippocampus may account for aberrant $\theta$ oscillations. Interestingly, the reduction of the GABAergic septohippocampal neuronal drive is observed in the absence of detectable cell loss, indicating that this effect is predominantly due to the functional regulation of their activity rather than neuronal death.

The mechanisms underlying the changes in the firing of medial septum-diagonal band GABAergic neurons are unclear. An examination of the local microenvironment around $\mathrm{A} \beta$ deposits in the hippocampus confirms that focal $A \beta 40$ and $A \beta 42$ injections in rats trigger long-lasting microglial activation (Weldon et al., 1998; Stéphan et al., 2003; Colom et al., 2010), as observed in the brain of AD patients (for review, see Akiyama et al., 2000). This microglial activation contributes to neuronal alterations, including a local loss of dendritic spines and axonal dystrophy, as well as modifications in the functional properties of neurons (Busche et al., 2008; Meyer-Luehmann et al., 2008). Interestingly, hippocampal $\mathrm{A} \beta$ accumulation triggers aberrant excitatory neuronal activity locally that is associated with remodeling inhibitory circuitry in the hippocampus (Palop et al., 2007). The CA1 $\theta$ rhythm could be affected by a decoupling of one or several autonomous hippocampal $\theta$ oscillators recently described (Goutagny et al., 2009). Thus, hippocampal A $\beta$ may play a role in altering the activity of septal neurons not only by acting on their axon terminals, but also by modifying the activity of hippocampal neurons. Increased hippocampal activity may also preferentially suppress the activity of $\theta$-modulated neurons of the medial septum-diagonal band (Dragoi et al., 1999; Hangya et al., 2009). Moreover, strong $\theta$ oscillations require the synchronization of septal populations by external inputs, such as hippocamposeptal projections (Wang, 2002). Alterations to this feedback projection could contribute to the decrease in the GABAergic septohippocampal projection and thus to anomalous hippocampal $\theta$ oscillations. 
One striking result of the present study is the contrast between the magnitude of the cognitive effects seen and the limited neuronal death observed in the septohippocampal pathway alteration. Moreover, hippocampal VGLUT1 depletions were not observed (see supplemental data, supplemental Fig. S8, available at www.jneurosci.org). No evidence of seizure was observed, suggesting no dramatic depletion in hippocampal GABAergic component. In the septum, the specific vulnerability of cholinergic neurons to $\mathrm{AD}$ has long been known and related to memory deficits (Davies and Maloney, 1976). More recently studies have enlightened the role of noncholinergic septal neurons in complex spatial memory processes (Dwyer et al., 2007). In agreement with this, little if any loss of ChAT expression was observed after hippocampal $A \beta$ injections, with an unexpected increase in septal parvalbumin immunoreactivity. Interestingly, GABAergic sprouting, ectopic neuropeptide $\mathrm{Y}$ expression, and an increase in calcium-binding protein immunoreactivity have already been characterized and interpreted as compensatory inhibitory mechanisms in various mouse models involving neuronal injury, epilepsy, and amyloid precursor protein (APP) overexpression (hAPPFAD mice) (Idrizbegovic et al., 2004; Lalonde et al., 2004; Palop et al., 2007) since they can attenuate neuronal overexcitation. This potential rescue process seems consistent with the transient upregulation of specific neurotransmitters observed in AD brains (Bell et al., 2003, 2007). In short, these studies have unraveled a pattern characterized by cholinergic and then glutamatergic/GABAergic upregulation, followed by cholinergic and then glutamatergic/GABAergic depletion. The present observations probably correspond to an intermediate stage, consisting of moderate septal cholinergic and hippocampal glutamatergic depletions concomitant with parvalbumin upregulation after an $\mathrm{A} \beta$ insult to the hippocampus.

In summary, this study reveals functional alterations in the activity of the septohippocampal network induced by hippocampal $\mathrm{A} \beta$ injection. These alterations comprise a selective reduction of inhibitory and rhythmic septohippocampal activity and anomalous hippocampal $\theta$ oscillation power and dynamic adaptation during a cognitive task that parallel the behavioral impairments in information processing observed in $\mathrm{A} \beta$-treated rats. The vulnerability of rhythmic septal GABAergic activity to hippocampal A $\beta$ pathology unveils an unconventional alteration of the neuronal processes associated with memory. These results, interpreted in light of the limited success of restorative cholinergic therapies in $\mathrm{AD}$, pinpoint new targets for intervention in $\mathrm{AD}$.

\section{References}

Akiyama H, Barger S, Barnum S, Bradt B, Bauer J, Cole GM, Cooper NR, Eikelenboom P, Emmerling M, Fiebich BL, Finch CE, Frautschy S, Griffin WS, Hampel H, Hull M, Landreth G, Lue L, Mrak R, Mackenzie IR, McGeer PL, et al. (2000) Inflammation and Alzheimer's disease. Neurobiol Aging 21:383-421.

Alreja M, Wu M, Liu W, Atkins JB, Leranth C, Shanabrough M (2000) Muscarinic tone sustains impulse flow in the septohippocampal GABA but not cholinergic pathway: implications for learning and memory. J Neurosci 20:8103-8110.

Ambrée O, Touma C, Görtz N, Keyvani K, Paulus W, Palme R, Sachser N (2006) Activity changes and marked stereotypic behavior precede Abeta pathology in TgCRND8 Alzheimer mice. Neurobiol Aging 27:955-964.

Apartis E, Poindessous-Jazat FR, Lamour YA, Bassant MH (1998) Loss of rhythmically bursting neurons in rat medial septum following selective lesion of septohippocampal cholinergic system. J Neurophysiol 79:1633-1642.

Arkhipov V, Kulesskaja N, Lebedev D (2008) Behavioral perseveration and impairment of long-term memory in rats after intrahippocampal injection of kainic acid in subconvulsive dose. Pharmacol Biochem Behav 88:299-305.
Bassant MH, Jouvenceau A, Apartis E, Poindessous-Jazat F, Dutar P, Billard JM (1998) Immunolesion of the cholinergic basal forebrain: effects on functional properties of hippocampal and septal neurons. Int J Dev Neurosci 16:613-632.

Bassant MH, Simon A, Poindessous-Jazat F, Csaba Z, Epelbaum J, Dournaud P (2005) Medial septal GABAergic neurons express the somatostatin sst $_{2 \mathrm{~A}}$ receptor: functional consequences on unit firing and hippocampal theta. J Neurosci 25:2032-2041.

Bell KFS, de Kort GJ, Steggerda S, Shigemoto R, Ribeiro-da-Silva A, Cuello AC (2003) Structural involvement of the glutamatergic presynaptic boutons in a transgenic mouse model expressing early onset amyloid pathology. Neurosci Lett 353:143-147.

Bell KFS, Bennett DA, Cuello AC (2007) Paradoxical upregulation of glutamatergic presynaptic boutons during mild cognitive impairment. J Neurosci 27:10810-10817.

Bland BH, Oddie SD (2001) Theta band oscillation and synchrony in the hippocampal formation and associated structures: the case for its role in sensorimotor integration. Behav Brain Res 127:119-136. Review.

Borhegyi Z, Varga V, Szilágyi N, Fabo D, Freund TF (2004) Phase segregation of medial septal GABAergic neurons during hippocampal theta activity. J Neurosci 24:8470-8479.

Brioni JD, Decker MW, Gamboa LP, Izquierdo I, McGaugh JL (1990) Muscimol injections in the medial septum impair spatial learning. Brain Res 522:227-234.

Bullock TH, Buzsáki G, McClune MC (1990) Coherence of compound field potentials reveals discontinuities in the CA1-subiculum of the hippocampus in freely-moving rats. Neuroscience 38:609-619.

Burgess N, Barry C, O'Keefe J (2007) An oscillatory interference model of grid cell firing. Hippocampus 17:801-812.

Busche MA, Eichhoff G, Adelsberger H, Abramowski D, Wiederhold KH, Haass C, Staufenbiel M, Konnerth A, Garaschuk O (2008) Clusters of hyperactive neurons near amyloid plaques in a mouse model of Alzheimer's disease. Science 321:1686-1689.

Buzsáki G (2002) Theta oscillations in the hippocampus. Neuron 33:325-340.

Buzsáki G, Draguhn A (2004) Neuronal oscillations in cortical networks. Science 304:1926-1929.

Canolty RT, Edwards E, Dalal SS, Soltani M, Nagarajan SS, Kirsch HE, Berger MS, Barbaro NM, Knight RT (2006) High gamma power is phaselocked to theta oscillations in human neocortex. Science 313:1626-1628.

Chappell J, McMahan R, Chiba A, Gallagher M (1998) A re-examination of the role of basal forebrain cholinergic neurons in spatial working memory. Neuropharmacology 37:481-487.

Chin J, Palop JJ, Puoliväli J, Massaro C, Bien-Ly N, Gerstein H, Scearce-Levie K, Masliah E, Mucke L (2005) Fyn kinase induces synaptic and cognitive impairments in a transgenic mouse model of Alzheimer's disease. J Neurosci 25:9694-9703.

Chrobak JJ, Napier TC (1992) Antagonism of GABAergic transmission within the septum disrupts working/episodic memory in the rat. Neuroscience 47:833-841.

Chrobak JJ, Stackman RW, Walsh TJ (1989) Intraseptal administration of muscimol produces dose-dependent memory impairments in the rat. Behav Neural Biol 52:357-369.

Clarke HF, Dalley JW, Crofts HS, Robbins TW, Roberts AC (2004) Cognitive inflexibility after prefrontal serotonin depletion. Science 304:878-880.

Colom LV, Castañeda MT, Bañuelos C, Puras G, García-Hernández A, Hernandez S, Mounsey S, Benavidez J, Lehker C (2010) Medial septal beta-amyloid 1-40 injections alter septo-hippocampal anatomy and function. Neurobiol Aging 31:46-57.

Davies P, Maloney AJ (1976) Selective loss of central cholinergic neurons in Alzheimer's disease. Lancet 2:1403.

Dragoi G, Carpi D, Recce M, Csicsvari J, Buzsáki G (1999) Interactions between hippocampus and medial septum during sharp waves and theta oscillation in the behaving rat. J Neurosci 19:6191-6199.

Dutar P, Lamour Y, Rascol O, Jobert A (1986) Septo-hippocampal neurons in the rat: further study of their physiological and pharmacological properties. Brain Res 365:325-334.

Dwyer TA, Servatius RJ, Pang KC. (2007) Noncholinergic lesions of the medial septum impair sequential learning of different spatial locations. J Neurosci 27:299-303.

Ekstrom AD, Caplan JB, Ho E, Shattuck K, Fried I, Kahana MJ (2005) Hu- 
man hippocampal theta activity during virtual navigation. Hippocampus 15:881-889.

Faure A, Verret L, Bozon B, El Tannir El Tayara N, Ly M, Kober F, Dhenain M, Rampon C, Delatour B (2009) Impaired neurogenesis, neuronal loss, and brain functional deficits in the APPxPS1-Ki mouse model of Alzheimer's disease. Neurobiol Aging. Advance online publication. Retrieved Feb. 22, 2010. doi:10.1016/j.neurobiolaging.2009.03.009.

Flood JF, Morley JE, Roberts E (1991) Amnestic effects in mice of four synthetic peptides homologous to amyloid beta protein from patients with Alzheimer disease. Proc Natl Acad Sci U S A 88:3363-3366.

Frotscher M, Léránth C (1985) Cholinergic innervation of the rat hippocampus as revealed by choline acetyltransferase immunocytochemistry: a combined light and electron microscopic study. J Comp Neurol 239:237-246.

Fyhn M, Molden S, Hollup S, Moser MB, Moser E (2002) Hippocampal neurons responding to first-time dislocation of a target object. Neuron 35:555-566.

Games D, Adams D, Alessandrini R, Barbour R, Berthelette P, Blackwell C, Carr T, Clemens J, Donaldson T, Gillespie F, Guido T, Hagopian S, Johnsonwood K, Khan K, Lee M, Leibowitz P, Lieberburg I, Little S, Masliah E, McConlogue L, et al. (1995) Alzheimer-type neuropathology in transgenic mice overexpressing V717F beta-amyloid precursor protein. Nature 373:523-527.

Givens BS, Olton DS (1990) Cholinergic and GABAergic modulation of medial septal area: effect on working memory. Behav Neurosci 104:849-855.

Gogolák G, Stumpf C, Petsche H, Sterc J (1968) The firing pattern of septal neurons and the form of the hippocampal theta wave. Brain Res 7:201-207.

Golde TE (2005) The Abeta hypothesis: leading us to rationally-designed therapeutic strategies for the treatment or prevention of Alzheimer disease. Brain Pathol 15:84-87.

Gorelova N, Reiner PB (1996) Role of the afterhyperpolarization in control of discharge properties of septal cholinergic neurons in vitro. J Neurophysiol 75:695-706.

Goutagny R, Jackson J, Williams S (2009) Self-generated theta oscillations in the hippocampus. Nat Neurosci 12:1491-1493.

Griffith WH, Matthews RT (1986) Electrophysiology of AChE-positive neurons in basal forebrain slices. Neurosci Lett 71:169-174.

Hale G, Good M (2005) Impaired visuospatial recognition memory but normal object novelty detection and relative familiarity judgments in adult mice expressing the APPswe Alzheimer's disease mutation. Behav Neurosci 119:884-891.

Hangya B, Borhegyi Z, Szilágyi N, Freund TF, Varga V (2009) GABAergic neurons of the medial septum lead the hippocampal network during theta activity. J Neurosci 29:8094-8102.

Hasselmo ME, Wyble BP, Wallenstein GV (1996) Encoding and retrieval of episodic memories: role of cholinergic and GABAergic modulation in the hippocampus. Hippocampus 6:693-708.

Hyman JM, Zilli EA, Paley AM, Hasselmo ME (2005) Medial prefrontal cortex cells show dynamic modulation with the hippocampal theta rhythm dependent on behavior. Hippocampus 15:739-749.

Idrizbegovic E, Bogdanovic N, Willott JF, Canlon B (2004) Age-related increases in calcium-binding protein immunoreactivity in the cochlear nucleus of hearing impaired C57BL/6J mice. Neurobiol Aging 25:10851093.

Jarrett JT, Lansbury PT Jr (1993) Seeding "one-dimensional crystallization" of amyloid: a pathogenic mechanism in Alzheimer's disease and scrapie?. Cell 73:1055-1058.

Jeewajee A, Lever C, Burton S, O'Keefe J, Burgess N (2008) Environmental novelty is signaled by reduction of the hippocampal theta frequency. Hippocampus 18:340-348.

Jones MW, Wilson MA (2005) Theta rhythms coordinate hippocampalprefrontal interactions in a spatial memory task. PLoS Biol 3:e402.

Köhler C, Chan-Palay V, Wu JY (1984) Septal neurons containing glutamic acid decarboxylase immunoreactivity project to the hippocampal region in the rat brain. Anat Embryol (Berl) 169:41-44.

Kumaran D, Maguire EA (2006) An unexpected sequence of events: mismatch detection in the human hippocampus. PLoS Biol 4:e424.

Lalonde J, Lachance PED, Chaudhuri A (2004) Monocular enucleation induces nuclear localization of calcium/calmodulin-dependent protein kinase IV in cortical interneurons of adult monkey area V1. J Neurosci 24:554-564.
Lenck-Santini PP, Rivard B, Muller RU, Poucet B (2005) Study of CA1 place cell activity and exploratory behavior following spatial and nonspatial changes in the environment. Hippocampus 15:356-369.

Manns JR, Squire LR (2001) Perceptual learning, awareness, and the hippocampus. Hippocampus 11:776-782.

Manns JR, Zilli EA, Ong KC, Hasselmo ME, Eichenbaum H (2007) Hippocampal CA1 spiking during encoding and retrieval: relation to theta phase. Neurobiol Learn Mem 87:9-20.

McCartney H, Johnson AD, Weil ZM, Givens B (2004) Theta reset produces optimal conditions for long-term potentiation. Hippocampus 14:684-687.

Meyer-Luehmann M, Spires-Jones TL, Prada C, Garcia-Alloza M, de Calignon A, Rozkalne A, Koenigsknecht-Talboo J, Holtzman DM, Bacskai BJ, Hyman BT (2008) Rapid appearance and local toxicity of amyloid-beta plaques in a mouse model of Alzheimer's disease. Nature 451:720-724

Morgan MA, Schulkin J, LeDoux JE (2003) Ventral medial prefrontal cortex and emotional perseveration: the memory for prior extinction training. Behav Brain Res 146:121-130.

Mormann F, Fell J, Axmacher N, Weber B, Lehnertz K, Elger CE, Fernández G (2005) Phase/amplitude reset and theta-gamma interaction in the human medial temporal lobe during a continuous word recognition memory task. Hippocampus 15:890-900.

Nagahara AH, McGaugh JL (1992) Muscimol infused into the medial septal area impairs long-term memory but not short-term memory in inhibitory avoidance, water maze place learning and rewarded alternation tasks. Brain Res 591:54-61.

Palop JJ, Chin J, Roberson ED, Wang J, Thwin MT, Bien-Ly N, Yoo J, Ho KO, Yu GQ, Kreitzer A, Finkbeiner S, Noebels JL, Mucke L (2007) Aberrant excitatory neuronal activity and compensatory remodeling of inhibitory hippocampal circuits in mouse

Paxinos G, Watson C (1986) In: The rat brain in stereotaxic coordinates, Ed 2. New York: Academic.

Perkel DH, Gerstein GL, Moore GP (1967) Neuronal spike trains and stochastic point processes. II. Simultaneous spike trains. Biophys J 7:419-440.

Petsche H, Stumpf C, Gogolak G (1962) The significance of the rabbit's septum as a relay station between the midbrain and the hippocampus. I. The control of hippocampus arousal activity by the septum cells. Electroencephalogr Clin Neurophysiol 14:202-211.

Peyrache A, Khamassi M, Benchenane K, Wiener SI, Battaglia FP (2009) Replay of rule-learning related neural patterns in the prefrontal cortex during sleep. Nat Neurosci 12:919-926.

Pinault D (1996) A novel single-cell staining procedure performed in vivo under electrophysiological control: morpho-functional features of juxtacellularly labeled thalamic cells and other central neurons with biocytin or Neurobiotin. J Neurosci Methods 65:113-136.

Ramadan W, Eschenko O, Sara SJ (2009) Hippocampal sharp wave/ripples during sleep for consolidation of associative memory. PLoS One 4:e6697.

Richter H, Ambrée O, Lewejohann L, Herring A, Keyvani K, Paulus W, Palme R, Touma C, Schäbitz WR, Sachser N (2008) Wheel-running in a transgenic mouse model of Alzheimer's disease: protection or symptom? Behav Brain Res 190:74-84.

Scheibel AB (1979) The hippocampus: organizational patterns in health and senescence. Mech Ageing Dev 9:89-102.

Sederberg PB, Kahana MJ, Howard MW, Donner EJ, Madsen JR (2003) Theta and gamma oscillations during encoding predict subsequent recall. J Neurosci 23:10809-10814.

Siapas AG, Lubenov EV, Wilson MA (2005) Prefrontal phase locking to hippocampal theta oscillations. Neuron 46:141-51.

Simon AP, Poindessous-Jazat F, Dutar P, Epelbaum J, Bassant MH (2006) Firing properties of anatomically identified neurons in the medial septum of anesthetized and unanesthetized restrained rats. J Neurosci 26:9038-9046.

Sirota A, Montgomery S, Fujisawa S, Isomura Y, Zugaro M, Buzsáki G (2008) Entrainment of neocortical neurons and gamma oscillations by the hippocampal theta rhythm. Neuron 60:683-697.

Small SA, Perera GM, DeLaPaz R, Mayeux R, Stern Y (1999) Differential regional dysfunction of the hippocampal formation among elderly with memory decline and Alzheimer's disease. Ann Neurol 45:466-472. 
Sotty F, Danik M, Manseau F, Laplante F, Quirion R, Williams S (2003) Distinct electrophysiological properties of glutamatergic, cholinergic and GABAergic rat septohippocampal neurons: novel implications for hippocampal rhythmicity. J Physiol 551:927-943.

Stepanichev MY, Zdobnova IM, Zarubenko II, Lazareva NA, Gulyaeva NV (2006) Studies of the effects of central administration of beta-amyloid peptide (25-35): pathomorphological changes in the Hippocampus and impairment of spatial memory. Neurosci Behav Physiol 36:101-106.

Stéphan A, Laroche S, Davis S (2001) Generation of aggregated betaamyloid in the rat hippocampus impairs synaptic transmission and plasticity and causes memory deficits. J Neurosci 21:5703-5714.

Stéphan A, Laroche S, Davis S (2003) Learning deficits and dysfunctional synaptic plasticity induced by aggregated amyloid deposits in the dentate gyrus are rescued by chronic treatment with indomethacin. Eur J Neurosci 17:1921-1927.

Stewart M, Fox SE (1989) Firing relations of medial septal neurons to the hippocampal theta rhythm in urethane anesthetized rats. Exp Brain Res 77:507-516.

Tort AB, Komorowski RW, Manns JR, Kopell NJ, Eichenbaum H (2009) Theta-gamma coupling increases during the learning of item-context associations. Proc Natl Acad Sci U S A. Advance online publication. Retrieved Feb. 19, 2010. DOI:10.1073/pnas.0911331106.

Tóth K, Borhegyi Z, Freund TF (1993) Postsynaptic targets of GABAergic hippocampal neurons in the medial septum-diagonal band of broca complex. J Neurosci 13:3712-3724.

Tóth K, Freund TF, Miles R (1997) Disinhibition of rat hippocampal pyramidal cells by GABAergic afferents from the septum. J Physiol 500: 463-474.
Vanderwolf CH (1969) Hippocampal electrical activity and voluntary movement in the rat. electroencephalogr Clin Neurophysiol 26:407-418.

Varga V, Hangya B, Kránitz K, Ludányi A, Zemankovics R, Katona I, Shigemoto R, Freund TF, Borhegyi Z (2008) The presence of pacemaker HCN channels identifies theta rhythmic GABAergic neurons in the medial septum. J Physiol 586:3893-3915.

Vertes RP, Kocsis B (1997) Brainstem-diencephalo-septohippocampal systems controlling the theta rhythm of the hippocampus. Neuroscience 81:893-926.

Vertes RP, Hoover WB, Viana Di Prisco G (2004) Theta rhythm of the hippocampus: subcortical control and functional significance. Behav Cogn Neurosci Rev 3:173-200.

Wang PN, Liu HC, Lirng JF, Lin KN, Wu ZA (2009) Accelerated hippocampal atrophy rates in stable and progressive amnestic mild cognitive impairment. Psychiatry Res 171:221-231.

Wang XJ (2002) Pacemaker neurons for the theta rhythm and their synchronization in the septohippocampal reciprocal loop. J Neurophysiol 87:889-900.

Weldon DT, Rogers SD, Ghilardi JR, Finke MP, Cleary JP, O’Hare E, Esler WP, Maggio JE, Mantyh PW (1998) Fibrillar beta-amyloid induces microglial phagocytosis, expression of inducible nitric oxide synthase, and loss of a select population of neurons in the rat CNS in vivo. J Neurosci $18: 2161-2173$.

Whishaw IQ, Tomie J (1997) Piloting and dead reckoning dissociated by fimbria-fornix lesions in a rat food carrying task. Behav Brain Res 89:87-97.

Winson J (1978) Loss of hippocampal theta rhythm results in spatial memory deficit in the rat. Science 201:160-163. 